\title{
Retina-Specific GTPase Accelerator RGS11/G $\beta 5 S / R 9 A P$ Is a Constitutive Heterotrimer Selectively Targeted to mGluR6 in ON-Bipolar Neurons
}

\author{
Yan Cao, ${ }^{1}$ Ikuo Masuho, ${ }^{1}$ Haruhisa Okawa, ${ }^{2}$ Keqiang Xie, ${ }^{1}$ Junko Asami, ${ }^{4}$ Paul J. Kammermeier, ${ }^{5}$ Dennis M. Maddox, ${ }^{6}$ \\ Takahisa Furukawa, ${ }^{7}$ Takayoshi Inoue, ${ }^{4}$ Alapakkam P. Sampath, ${ }^{2,3}$ and Kirill A. Martemyanov ${ }^{1}$ \\ ${ }^{1}$ Department of Pharmacology, University of Minnesota, Minneapolis, Minnesota 55455, ${ }^{2}$ Neuroscience Graduate Program and ${ }^{3}$ Zilkha Neurogenetic \\ Institute and Department of Physiology and Biophysics, University of Southern California, Los Angeles, California 90089, ${ }^{4}$ Department of Biochemistry and \\ Cellular Biology, National Institute of Neuroscience, National Center of Neurology and Psychiatry, Kodaira, Tokyo 187-8502, Japan, ${ }^{5}$ Department of \\ Pharmacology and Physiology, University of Rochester Medical Center, Rochester, New York 14642, ${ }^{6}$ The Jackson Laboratory, Bar Harbor, Maine 04609, \\ and ${ }^{7}$ Department of Developmental Biology, Osaka Bioscience Institute, Suita, Osaka 565-0874, Japan
}

Members of the R7 family of the regulators of G-protein signaling (R7 RGS) proteins form multi-subunit complexes that play crucial roles in processing the light responses of retinal neurons. The disruption of these complexes has been shown to lead to the loss of temporal resolution in retinal photoreceptors and deficient synaptic transmission to downstream neurons. Despite the well established role of one member of this family, RGS9-1, in controlling vertebrate phototransduction, the roles and organizational principles of other members in the retina are poorly understood. Here we investigate the composition, localization, and function of complexes containing RGS11, the closest homolog of RGS9-1. We find that RGS11 forms a novel obligatory trimeric complex with the short splice isoform of the type 5 G-protein $\beta$ subunit (G $\beta 5$ ) and the RGS9 anchor protein (R9AP). The complex is expressed exclusively in the dendritic tips of ON-bipolar cells in which its localization is accomplished through a direct association with mGluR6, the glutamate receptor essential for the 0Nbipolar light response. Although association with both R9AP and mGluR6 contributed to the proteolytic stabilization of the complex, postsynaptic targeting of RGS11 was not determined by its membrane anchor R9AP. Electrophysiological recordings of the light response in mouse rod ON-bipolar cells reveal that the genetic elimination of RGS11 has little effect on the deactivation of $\mathrm{G} \alpha_{\mathrm{o}}$ in dark-adapted cells or during adaptation to background light. These results suggest that the deactivation of mGluR6 cascade during the light response may require the contribution of multiple GTPase activating proteins.

\section{Introduction}

Regulators of G-protein signaling (RGS) play crucial roles in controlling signal transduction via heterotrimeric G-proteins. Acting to stimulate G-protein inactivation by accelerating their GTP hydrolysis rates, RGS proteins markedly shape the kinetics of cellular responses mediated by the G-protein pathways (Ross and Wilkie, 2000; Hollinger and Hepler, 2002).

In mammals, the R7 family of RGS proteins play important roles in neural processing in which they regulate vision (Burns and Arshavsky, 2005), locomotion (Blundell et al., 2008), and reward behavior (Hooks et al., 2008). Four members of the R7 RGS family, RGS6, RGS7, RGS9, and RGS11, share a common

Received March 22, 2009; revised May 27, 2009; accepted June 17, 2009.

This work was supported by National Institutes of Health Grants EY018139 (K.A.M.), EY017606 (A.P.S.), and EY016313 (D.M.M.), National Institute of Biomedical Innovation Grant 05-32 (T.I.), and a Karl Kirschgessner Foundation vision research grant (A.P.S.). We thank Dr. William Simonds (National Institutes of Health, Bethesda, MD) for the generous gift of anti-RGS7 and anti-G $\beta 5$ antibodies and Dr. Jason Chen (Virginia Commonwealth University, Richmond, VA) for providing $\mathrm{G} \beta 5$ knock-out mice. We also thank Gilbert Ahlstrand at the Imaging (enter, University of Minnesota (St. Paul, MN) for the help with electron microscopy.

Correspondence should be addressed to Dr. Kirill A. Martemyanov, Department of Pharmacology, 6-120 Jackson Hall, 321 Church Street SE, Minneapolis, MN 55455. E-mail: martemyanov@umn.edu.

DOI:10.1523/JNEUROSCI.1367-09.2009

Copyright $\odot 2009$ Society for Neuroscience $\quad$ 0270-6474/09/299301-13\$15.00/0 multidomain organization and form obligate complexes with type 5 G-protein $\beta$ subunit (G $\beta 5$ ) (Cabrera et al., 1998; Snow et al., 1998; Makino et al., 1999). The knock-out of G $\beta 5$ in mice destabilizes all R7 RGS proteins, severely downregulating their expression (Chen et al., 2003). In addition to G $\beta 5$, R7 RGS proteins bind to two novel homologous proteins: RGS9 anchor protein (R9AP) and R7 binding protein (R7BP) (Hu and Wensel, 2002; Drenan et al., 2005; Martemyanov et al., 2005). The contribution of the individual subunits and the functional roles of the R7 RGS are the best studied for the RGS9-1/G $\beta 5$ L/R9AP complex that determines the duration of retinal photoreceptor responses to light. The catalytic subunit of the complex RGS9-1 acts as a specific GTPase activating protein (GAP) for G-protein transducin that, during light excitation, transmits signal from the G-protein-coupled receptor rhodopsin to the effector, a cGMP phosphodiesterase, allowing the timely response inactivation. The expression level of RGS9-1 and hence the speed of the signal termination is determined by its association with G $\beta 5$ and R9AP subunits. In addition, R9AP is responsible for the targeting of the complex to the compartment of the cell harboring the components of visual signal transduction cascade (Burns and Arshavsky, 2005). 
The functional roles and organizational principles of other members of R7 RGS family in the retina are less well understood. Studies with G $\beta 5$ knock-out mice indicate that elimination of R7 RGS expression causes synaptic deficits and abolishes transmission between photoreceptors and downstream ON-bipolar neurons (Rao et al., 2007), suggesting that these proteins play crucial roles in retinal wiring and perhaps in the regulation of lightdependent signaling. Indeed, both RGS7 and RGS11 were reported to be localized in dendrites of ON-bipolar cells (Morgans et al., 2007; Rao et al., 2007). However, details pertaining to their organization and function are essentially unknown.

Here, we investigated the subunit composition, expression, localization, and function of RGS11 in the retina. We find that RGS11 is expressed exclusively in retinal ON-bipolar neurons in which it forms complexes with G $\beta 5$ S and R9AP. As for RGS9-1, R9AP was found to be required for maintaining proteolytic stability of the RGS11/G $\beta 5 S$ complex. However, in contrast to the photoreceptors, targeting of RGS11 to the dendritic tips of ON-bipolar cells was not mediated by R9AP but rather was accomplished via direct interaction with mGluR6, the principle receptor mediating synaptic communication between photoreceptors and ON-bipolar cells. RGS11 was found to be a potent GAP for $\mathrm{G} \alpha_{\mathrm{o}}$, but its elimination in mice was not sufficient for altering kinetics of $\mathrm{ON}$-bipolar cell responses to light, suggesting that mGluR6-G $\alpha_{\mathrm{o}}$ cascade can be regulated by multiple RGS proteins.

\section{Materials and Methods}

DNA constructs, antibodies, and mouse strains. The cloning of full-length mouse R9AP and G $\beta 5$ S in a mammalian expression vector pcDNA3.1 was described previously (Song et al., 2006; Anderson et al., 2007a). Mouse full-length RGS11 (Martemyanov et al., 2005) was subcloned into a pcDNA3.1/V5-His-TOPO (Invitrogen) expression vector according to the specifications of the manufacturer. The rat mGluR6 coding sequence was subcloned into pcDNA3.1 at XhoI and HindIII restriction sites using the Failsafe PCR system (Epicenter Biotechnologies), from the original mGluR6/pBluescript clone (provided by Y. Nakajima, Kyoto University, Kyoto, Japan).

The generation of rabbit anti-R9AP (against amino acids 144-223) (Keresztes et al., 2003), sheep anti-RGS9c (Makino et al., 1999), sheep anti-RGS11 CT (Cao et al., 2008), and rabbit anti-RGS11 CT (Song et al., 2007) antibodies was described previously. Rabbit anti-RGS7 (7RC1) and anti-G $\beta 5$ (SGS and ATDG) were generous gifts from Dr. William Simonds [National Institute of Diabetes and Digestive and Kidney Diseases/National Institutes of Health (NIH), Bethesda, MD]. The antimGluR6 antibody was generated in guinea pig against a synthetic peptide with the sequence ${ }_{853}$ KKTSTMAAPPKSENSEDAK $_{871}$ (Sato et al., 2008). Mouse monoclonal anti- $\beta$-actin (clone AC- 15 ; Sigma), mouse monoclonal anti-PKC $\alpha$ (ab11723; Abcam), mouse anti-CtBP2 (612044; BD Biosciences), mouse monoclonal anti-calbindin D-28K (clone CB-955, C9848; Sigma), and rabbit anti-G $\alpha_{\mathrm{o}}$ (K-20; Santa Cruz Biotechnology) were purchased.

The generation and characterization of mouse knock-out strains with targeted disruptions of G $\beta 5$ (Chen et al., 2003; Cao et al., 2008), R9AP (Keresztes et al., 2004), and RGS11 (Cao et al., 2008) genes was described previously. The nob4 strain of mice carrying homozygous mGluR6 allele with a loss-of-function point mutation (Pinto et al., 2007) was obtained from the National Institutes of Health Neurogenomics Project at Northwestern University (Evanston, IL). The nob3 [B6.B10(D2)-Grm6 $6^{\text {nob3/PJN }}$ ] mice carrying a frame-shifting mutation in the mGluR6 gene that leads to early termination at amino acid 264 (Maddox et al., 2008) were obtained from The Jackson Laboratory. Mice used in the study were 1-3 months old and were maintained on a diurnal $12 \mathrm{~h}$ light/dark cycle. Procedures involving mice strictly followed NIH guidelines and were approved by the Institutional Animal Care and Use Committee at the University of Minnesota and the University of Southern California.
Cell culture and transfection. NG108-15 cells were purchased from American Type Culture Collection and maintained in DMEM (Invitrogen) supplemented with $10 \%$ fetal bovine serum, $0.1 \mathrm{~mm}$ sodium hypoxanthine, $0.4 \mu \mathrm{M}$ aminopterin, $16 \mu \mathrm{M}$ thymidine, $100 \mathrm{U}$ penicillin, and $100 \mu \mathrm{g}$ of streptomycin. HEK293T cells were obtained from Clontech and cultured at $37^{\circ} \mathrm{C}$ and $5 \% \mathrm{CO}_{2}$ in DMEM supplemented with antibiotics, 10\% FBS, and 4 mM L-glutamine. Both NG108-15 and HEK293T cells were transfected at $\sim 70 \%$ confluency using Lipofectamine LTX (Invitrogen) according to the protocol of the manufacturer. Cells were harvested $48 \mathrm{~h}$ after transfection.

Pulse-chase degradation assay. Experiments to evaluate the stability of proteins to proteolytic degradation were performed in NG108-15 cells as described previously (Anderson et al., 2007b). Briefly, cells grown in T-25 flasks were transfected with RGS11 and G $\beta 5$ S constructs with or without R9AP and mGluR6 plasmid. Twenty-four hours after transfection, cells were metabolically labeled by $300 \mu \mathrm{Ci}$ of $\left[{ }^{35} \mathrm{~S}\right]$ methionine and cysteine (NEG772; PerkinElmer Life and Analytical Sciences) for $40 \mathrm{~min}$. The media were replaced to fully supplemented media, and cells were collected at the indicated intervals and lysed in $900 \mu \mathrm{l}$ of radioimmunoprecipitation assay buffer (50 mm Tris- $\mathrm{HCl}, \mathrm{pH} 7.8,300 \mathrm{~mm} \mathrm{NaCl}, 1 \mathrm{~mm}$ EDTA, $1 \%$ Triton X-100, 0.5\% sodium deoxycholate, and 0.1\% SDS) supplemented with protease inhibitors (Complete; Roche). RGS11 was precipitated from the cellular lysates by $3 \mu \mathrm{g}$ of sheep anti-RGS11 CT antibodies coupled to $10 \mu \mathrm{l}$ of protein $\mathrm{G}$ beads for $1 \mathrm{~h}$ at $4^{\circ} \mathrm{C}$. The beads were washed, and immunoprecipitated proteins were eluted from the beads by SDS sample buffer, resolved by the SDS-PAGE, and transferred to a polyvinylidene difluoride (PVDF) membrane (Bio-Rad). The membrane was air dried and incubated on a phosphor imaging screen overnight. This screen was then scanned using a STORM phosphor imager (Molecular Dynamics), and the bands were quantified using ImageQuant Software (Molecular Dynamics). Each experiment was repeated at least twice.

Immunoprecipitation and Western blotting. For coimmunoprecipitation experiments from transfected cells, HEK293T cells from one well of a six-well plate were lysed using $500 \mu \mathrm{l}$ of PBS (Thermo Fisher Scientific) supplemented with an additional $150 \mathrm{~mm} \mathrm{NaCl}, 0.5 \%$ $n$-dodecanoylsucrose (EMD Biosciences), and Complete protease inhibitors (Roche). The homogenate was centrifuged at $15,000 \times g$ for $15 \mathrm{~min}$ at $4^{\circ} \mathrm{C}$. The supernatant was incubated with $3 \mu \mathrm{g}$ of sheep anti-RGS11 CT antibody and $20 \mu \mathrm{l}$ of $50 \%$ protein G slurry (GE Healthcare) on a rocker at $4^{\circ} \mathrm{C}$ for $1 \mathrm{~h}$. After three washes with the lysis buffer, the proteins were eluted from beads with $50 \mu$ l of SDS sample buffer containing $8 \mathrm{M}$ urea by incubation for $30 \mathrm{~min}$ at $42^{\circ} \mathrm{C}$. Proteins retained by the beads were analyzed with SDS-PAGE, followed by Western blotting using specific antibodies.

Immunoprecipitation of R9AP, RGS9, and RGS11 from tissues was performed as described previously (Song et al., 2007). Whole retinas and other tissues were removed from mice and lysed by sonication in ice-cold PBS (Invitrogen) supplemented with $150 \mathrm{~mm} \mathrm{NaCl}, 1 \%$ Triton X-100, and Complete protease inhibitor tablets (Roche). Cleared lysates were incubated with 3-5 $\mu \mathrm{g}$ of rabbit anti-R9AP, sheep anti-RGS9c, or sheep anti-RGS11 CT antibodies and $20 \mu \mathrm{l}$ of $50 \%$ protein G beads (GE Healthcare) for $1 \mathrm{~h}$ at $4^{\circ} \mathrm{C}$. Total protein concentration in samples was measured by the bicinchoninic acid assay (Pierce). After three washes with ice-cold binding buffer, proteins bound to the beads were eluted with an SDS sample buffer (62 mM Tris, $10 \%$ glycerol, $2 \%$ SDS, and $5 \%$ $\beta$-mercaptoethanol) and analyzed by $4-20 \%$ PAGE (Lonza). Protein bands were transferred onto PVDF membranes and subjected to Western blot analysis using HRP-conjugated secondary antibodies and ECL West Pico (Pierce) detection system.

Immunohistochemistry. Immunohistochemical detection of proteins in retinal sections was described previously (Cao et al., 2008). Briefly, eyecups were dissected from mice, fixed for $15 \mathrm{~min}$ with $4 \%$ paraformaldehyde (PFA), cryoprotected with $30 \%$ sucrose in PBS for $2 \mathrm{~h}$ at room temperature, and embedded in OCT. Twelve micrometer frozen sections were obtained by cryostat. Sections were blocked in PT1 ( $1 \times$ PBS with $0.1 \%$ Triton X-100 and $10 \%$ goat serum) for $1 \mathrm{~h}$ and incubated with primary antibody in PT2 $(1 \times$ PBS with $0.1 \%$ Triton $\mathrm{X}-100$ and $2 \%$ goat serum) for $1 \mathrm{~h}$, washed four times with PT2, and 
incubated with fluorophore-conjugated secondary antibodies in PT2 for $1 \mathrm{~h}$. For double staining, primary antibodies raised in the different species were used except for RGS11/RGS7 double staining when both antibodies were from rabbit. In this case, RGS7 antibodies were directly labeled with Dylight 549 using Microscale Antibody Labeling kit (Thermo Fisher Scientific). Sections were washed three times for 5 min and mounted in Mounting Medium (Pierce). Images were taken by the Olympus Fluoview 1000 confocal microscope. The following dilutions of the antibodies were used: rabbit anti-RGS7 (7RC1), 1:200; rabbit anti-RGS11 CT, 1:500; rabbit anti-G $\beta 5$ (ATDG), 1:500; rabbit anti-R9AP, 1:500; mouse anti-PKC $\alpha, 1: 100$; mouse antiCtBP2, 1:1000; rabbit anti-G $\alpha_{\mathrm{o}}, 1: 500$; mouse anti-calbindin, 1:100; guinea pig anti-mGluR6, 1:1000; goat anti-rabbit Alexa 488, 1:1000; goat anti-mouse Alexa 546, 1:1000, and goat anti-guinea pig Alexa 546, 1:1000.

Quantitative analysis of immunofluorescence from confocal images was performed using MetaMorph 7.5 software package. For each genotype, immunohistochemical staining was repeated at least twice on two to three sections obtained from two individual animals. Sections were double stained for a marker protein (CtBP2 or mGluR6) and the protein of interest. The region of interest (outer plexiform layer) was determined by the positive staining in a channel containing marker protein and used as a reference for the normalization of the recorded fluorescence intensity in the channel containing protein being measured. The fluorescence intensity within synaptic puncta was analyzed using line-scan mode. A $2.48-\mu \mathrm{m}$-long line was placed across individual punctum using mGluR6-positive channel as a reference. The distribution of the maximal intensities along this line was determined in both channels, averaged across 10 individual puncta, and reported as pixel versus distance plot. The parameters of the peaks of the intensity distribution in each channel were plotted and analyzed using OriginPro 7.5 software.

Electron microscopy. Eyes were enucleated, cleaned of extraocular tissue, and fixed for $30 \mathrm{~min}$ in cacodylate-buffered Karnovsky's fixative. The eye globe was then hemisected along the vertical meridian and was allowed to fix overnight at the same buffer. Eye cups were rinsed with $0.1 \mathrm{M}$ phosphate buffer and postfixed in $2 \%$ osmium tetroxide for $45 \mathrm{~min}$, then gradually dehydrated in an increasing acetone series (25-100\%), and finally embedded in Embed 812 epoxy resin. Blocks were cut to yield $\sim 60$-nm-thick sections, which were stained with $3 \%$ aqueous uranyl acetate for $20 \mathrm{~min}$, rinsed three times in distilled water, followed by staining with Sato lead stain for $3 \mathrm{~min}$, rinsed three times in distilled water, and finally air dried. Sections were viewed in an FEI C12 transmission electron microscope at a $60 \mathrm{kV}$ accelerating voltage. Images were recorded with a Maxim DL digital capture system. For the quantification of the deficits in the synapse morphology, rod terminals containing only one triad were considered. Additionally, to be included in the analysis, those terminals had to contain two easily identifiable features: doublet of the horizontal cell dendrites and a synaptic ribbon. The numbers of the counted triads in each genotype that conform to these criteria are reported in the graph (see Fig. $4 C$ ). If in addition to these elements the triads contained easily identifiable bipolar cell dendrites, the morphology of this synapse was considered normal. In case no bipolar cell dendrites could be identified within the triad, the synapses were counted as deficient.

In situ hybridization. Preparation of digoxigenin-UTP-labeled RNA probes and in situ hybridization were performed as described previously with slight modifications (Inoue et al., 1998). In brief, eyes of 2-monthold mice were dissected and fixed with $4 \%$ PFA in PBS overnight at $4^{\circ} \mathrm{C}$. Fixed eye samples were then washed by PBS, followed by treatments of a graded series of sucrose solutions (5-10-15-20\%) in PBS, embedded in Tissue-Tek optimal cutting temperature compound (Sakura Finetek USA), and frozen on a block of dry ice. Twelve micrometer sections were then collected on glass slide coated with VECTABOND Reagent (Vector Laboratories). To obtain highly sensitive and stringent results, the steps of hybridization and posthybridization wash were performed at $65^{\circ} \mathrm{C}$ to avoid nonspecific bindings of probes, and the detection periods of each antisense and sense probe were always equal. By using a highly sensitive detection reagent containing $10 \%$ polyvinyl alcohol, signal was boosted, yielding densely packed punctated signals around the cell nuclei. Stained sections were photographed under the bright-field illumination using a Carl Zeiss Axioplan-2 upright microscope equipped with a color CCD camera.

Quantitative real-time reverse transcription-PCR experiments. Total RNA was extracted from retinas using RNA isolation kit (Stratagene), and $0.08 \mu \mathrm{g}$ of RNA was used to perform quantitative real-time reverse transcription (QRT)-PCR using SYBR Green QRT-PCR kit (Stratagene). The 5' primer GCCCACTTCATGGACTTT and 3' primer GGCCAGGAACTGCTGATACA were used, which had been designed to be specific to RGS11. PCR cycling and detection was performed on the Stratagene Mx3005P Real-Time PCR System, with quantification analysis by Stratagene MxPro QPCR software. In addition to using equal amounts of total RNA as defined by ultraviolet spectroscopy, we also included internal reference controls to account for the integrity of mRNA: amplification of $\beta$-actin mRNAs. Amplification of $\beta$-actin mRNA was used as endogenous reference for normalization RGS11 mRNA amplification.

Recombinant proteins and in vitro GTPase assays. Recombinant RGS7, RGS9-1, and RGS11 were coexpressed with G $\beta 5$ S using Sf9-baculovirus system as described previously (Martemyanov et al., 2005). Protein complexes were purified by Ni-NTA chromatography taking advantage of the His tag engineered at the $\mathrm{N}$ terminus of RGS proteins as described previously (Skiba et al., 2001).

GAP activity on $\mathrm{G} \alpha_{\mathrm{o}}$ was determined using the solution single turnover technique (Ross, 2002). $\mathrm{G} \alpha_{\mathrm{o}}$ subunit $(1 \mu \mathrm{M})$ was incubated with 2 $\mu \mathrm{M}\left[\gamma^{-}{ }^{32} \mathrm{P}\right] \mathrm{GTP}\left(\sim 10^{5} \mathrm{dpm} / \mathrm{sample}\right)$ in $\mathrm{Mg}^{2+}$-free charging buffer containing $50 \mathrm{~mm} \mathrm{Na}$ HEPES, pH 7.5, $100 \mathrm{~mm} \mathrm{NaCl}, 0.05 \% \mathrm{C}_{12} \mathrm{E}_{10}, 5 \mu \mathrm{g} / \mathrm{ml}$ $\mathrm{BSA}, 1 \mathrm{~mm}$ DTT, and $10 \mathrm{~mm}$ EDTA at room temperature for $20 \mathrm{~min}$. Reactions were started by combining $10 \mu \mathrm{l}$ of the charged $\mathrm{G} \alpha_{\mathrm{o}}$ with $20 \mu \mathrm{l}$ of the GTPase buffer (10 mm Tris HCl, pH 7.8, $100 \mathrm{~mm} \mathrm{NaCl}, 8 \mathrm{~mm}$ $\mathrm{MgCl}_{2}$, and $1 \mathrm{~mm}$ DTT) containing $1 \mu \mathrm{M}$ RGS7, $1 \mu \mathrm{M}$ RGS9-1 plus $20 \mu \mathrm{M}$ phosphodiesterase $\gamma(\mathrm{PDE} \gamma)$ (63-87 aa), or $1 \mu \mathrm{M}$ RGS11. Reactions were stopped by adding $100 \mu \mathrm{l}$ of $6 \%$ perchloric acid, and the ${ }^{32} \mathrm{P}_{\mathrm{i}}$ formation was measured in the supernatant with activated charcoal. The rates of GTP hydrolysis were determined by a single-exponential fit of the reaction time course. Catalytic efficiencies of RGS proteins were compared by calculating the parameter $k_{\mathrm{GAP}}$, defined as the difference between the rates of G-protein GTPase activity in the presence of an RGS protein and the basal GTPase activity of the same G-protein (Krumins and Gilman, 2002).

Single-cell electrophysiological recordings. Whole-cell voltage-clamp recordings ( $V_{\mathrm{m}}$ of $-60 \mathrm{mV}$ ) from rod bipolar cells in 200- $\mu \mathrm{m}$-thick darkadapted retinal slices were made as described previously (Sampath et al., 2005). The internal solution for these experiments consisted of the following: $125 \mathrm{~K}$-aspartate, $10 \mathrm{KCl}, 10 \mathrm{HEPES}, 5 \mathrm{~N}$-methyl-D-glucamine (NMG)-N-hydroxyethylethylenediaminetriacetic acid, $0.5 \mathrm{CaCl}_{2}, 1$ ATP-Mg, and 0.2 GTP-Mg, pH adjusted to 7.2 with NMG-OH. Flash families were measured in response to a $10 \mathrm{~ms}$ flash from a blue lightemitting diode $\left(\lambda_{\max }\right.$ of $\sim 470 \mathrm{~nm}$ ) whose strength was varied. Average responses per photon were calculated by averaging the response per photon across the dimmest responses of each cell [i.e., those between $5 \%$ and $25 \%$ of maximal amplitude (Sampath et al., 2005)]. The gain of the average response per photon was also determined during exposure to background light, delivered also by the blue light-emitting diode.

\section{Results}

RGS11 and R9AP are expressed exclusively in the retina and form complexes at the photoreceptor-to-bipolar synapse between photoreceptor and bipolar cells

Previous work showing that elimination of R9AP downregulated RGS11 expression in the retina (Cao et al., 2008) suggested that in vivo R9AP could be controlling RGS11 in addition to the well studied regulation of RGS9-1. Therefore, we compared the expression profiles of R9AP and RGS11 at the protein level and characterized their interaction. Western blotting with specific anti-RGS11 antibodies was used to detect RGS11 protein in lysates prepared from various mouse 
A

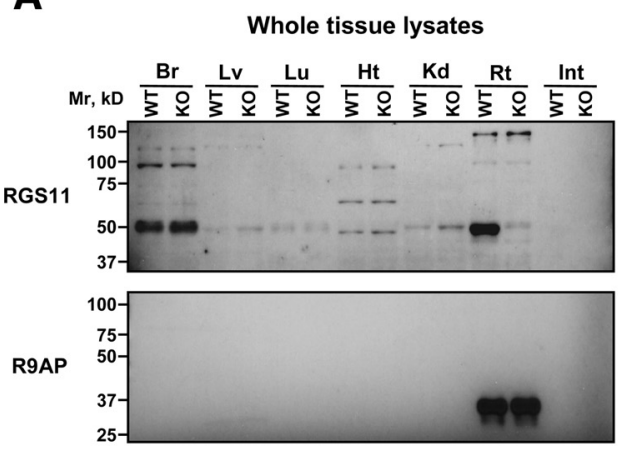

IP: RGS11 Ab

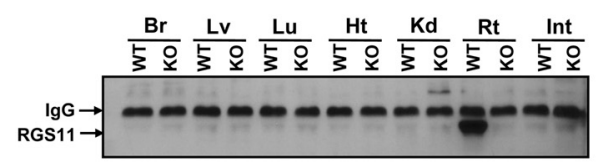

Rt Ctx Crb Olf Str Hpc Mbr

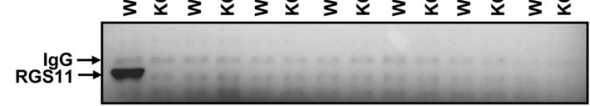

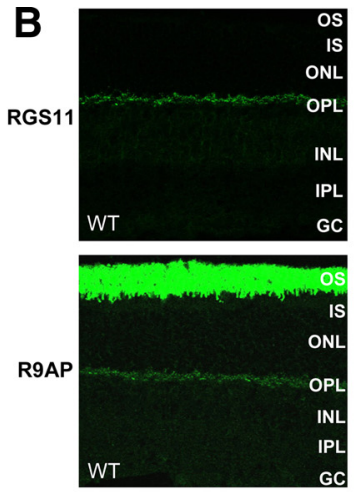
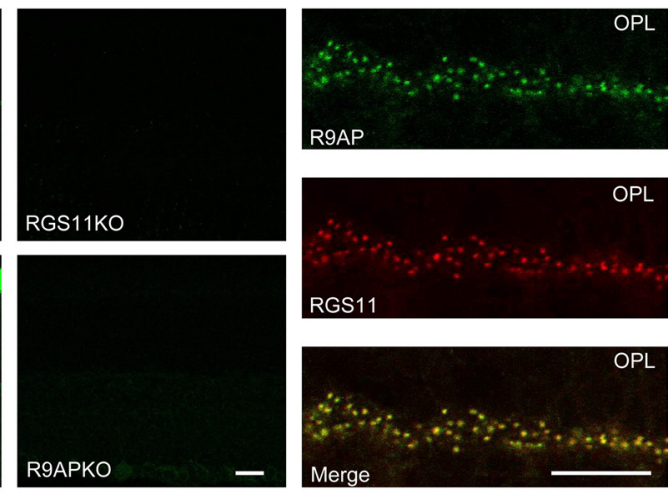

C

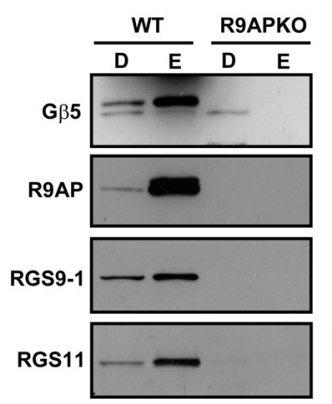

IP: RGS11 Ab

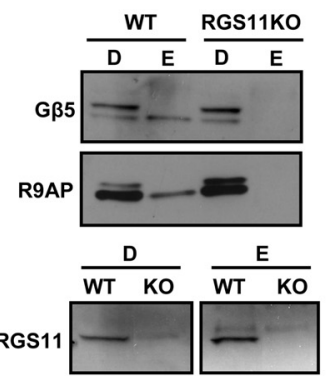

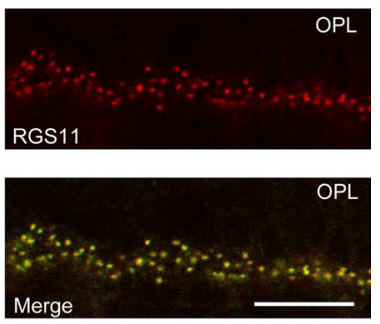

IP: RGS9-1 Ab

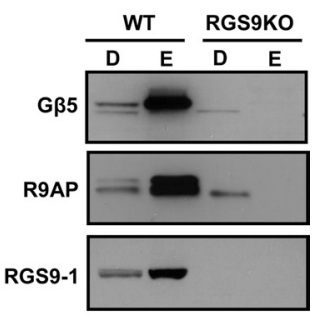

Figure 1. Characterization of RGS11 expression and its complex formation with G $\beta 5$ and R9AP subunits. $\boldsymbol{A}$, Top, Western blot analysis of RGS11 and R9AP protein expression in whole-tissue lysates prepared from different tissues. Tissues were lysed in buffer containing $1 \%$ Triton X-100 as described in Materials and Methods, and $5 \mu \mathrm{g}$ of total protein was loaded in each lane after supplementation with SDS sample buffer. Equal amount of lysate prepared from RGS11 knock-out tissues (K0) served as a control for nonspecific cross-reactivity of sheep anti-RGS11 CT antibodies used to probe the blot. In parallel, an identical blot was probed with rabbit anti-R9AP antibodies. Bottom, Detection of RGS11 protein expression in various tissues and brain regions by Western blotting after immunoprecipitation. Five micrograms of sheep anti-RGS11 CT antibodies was used for the immunoprecipitation (IP) experiment, and the blots were probed with rabbit anti-RGS11 CT antibodies. Br, Brain; Lv, liver; Lu, lung; Ht, heart; Kd, kidney; Rt, retina; Int, intestine; Ctx, cortex; Crb, cerebellum; Olf, olfactory bulb; Str, striatum; Hpc, hippocampus; Mbr, midbrain. B, Colocalization of RGS11 and R9AP at the outer plexiform layer in the retina. Retinal sections prepared from wild-type (WT) and knock-out mice were stained using rabbit anti-RGS11 CT and anti-R9AP antibodies. Immunofluorescence signals overlapped extensively in the outer plexiform layer. OS, Outer segment; IS, inner segment; 0NL, outer nuclear layer; OPL, outer plexiform layer; INL, inner nuclear layer; IPL, inner plexiform layer; GC, ganglion cells. Scale bars: left, $20 \mu \mathrm{m}$; right, $10 \mu \mathrm{m}$. C, Coimmunoprecipitation of RGS11 with its subunits: R9AP and G $\beta 5 S$. Total retina lysates prepared as described in Materials and Methods were subjected to immunoprecipitation with indicated antibodies. Proteins preset in whole-cell detergent extracts (D) and eluates from the beads (E) were detected by Western blotting with antibodies against individual proteins.

tissues (Fig. 1A, top). To account for potential variability in size of RGS11 polypeptides attributable to alternative splicing (Giudice et al., 2001) or potential posttranslational modifications, in a parallel experiment, we have used lysates prepared from the tissues of RGS11 knock-out mice as a control for nonspecific antibody reactivity. The results indicate that specific RGS11 reactivity could be detected only in the retina. Because RGS11 mRNA was detected previously in the brain (Gold et al., 1997; Snow et al., 1998), we also addressed a possibility that analysis of total brain lysates by direct Western blotting might not have revealed low levels of RGS11 restricted to discrete brain region(s). In these experiments, we have dissected multiple brain structures and enriched RGS11 in the samples by conducting immunoprecipitation (Fig. 1A, bottom). Although this resulted in robust detection of RGS11 in the retina, no RGS11 was detected in the analyzed brain regions. Notably, in the brain, antibodies produced a signal in the range of RGS11 molecular mass. However, this reactivity was also present in the knock-out samples and could not be immunoprecipitated, suggesting the signal to be of nonspecific nature. An identical tissue distribution profile was also observed for R9AP, indicating that the expression of both RGS11 and R9AP is restricted to the retina.

Coexpression of RGS11 and R9AP in the retina is in agreement with our previous observations that these two proteins can form a complex in vitro (Martemyanov et al., 2005) and in vivo (Song et al., 2007). However, whereas R9AP is accepted to be present specifically in the outer segments of photoreceptors in which it complexes with a key phototransduction regulator, RGS9-1/G 35 L (Hu and Wensel, 2002; Martemyanov et al., 2003; Keresztes et al., 2004), RGS11 was reported instead to be enriched in the synaptic region dendrites of downstream ONbipolar cells (Morgans et al., 2007; Rao et al., 2007). These observations prompted us to address the precise composition and localization of the R9AP/RGS11 complex. First, we have reexamined the distribution of RGS11 and R9AP by immunohistochemistry using the most stringent controls in which staining was performed with retinas from knock-out mice lacking either R9AP or RGS11 in parallel with wild-type retinas. Results presented in Figure $1 B$ reveal that, in addition to photoreceptor outer segments, a weak but specific R9AP staining was also present in the outer plexiform layer, a site of RGS11 exclusive localization. Double labeling followed by high-power confocal microscopy confirmed that R9AP and RGS11 colocalize at the characteristic synaptic puncta (Fig. $1 B$ ).

We next studied the association of the RGS11/R9AP complex with $G \beta 5$, an obligatory subunit that was found to be essential for the expression of all R7 RGS proteins (Fig. 1C). Indeed, R9AP immunoprecipitation, in addition to RGS9-1 and RGS11, pulled 

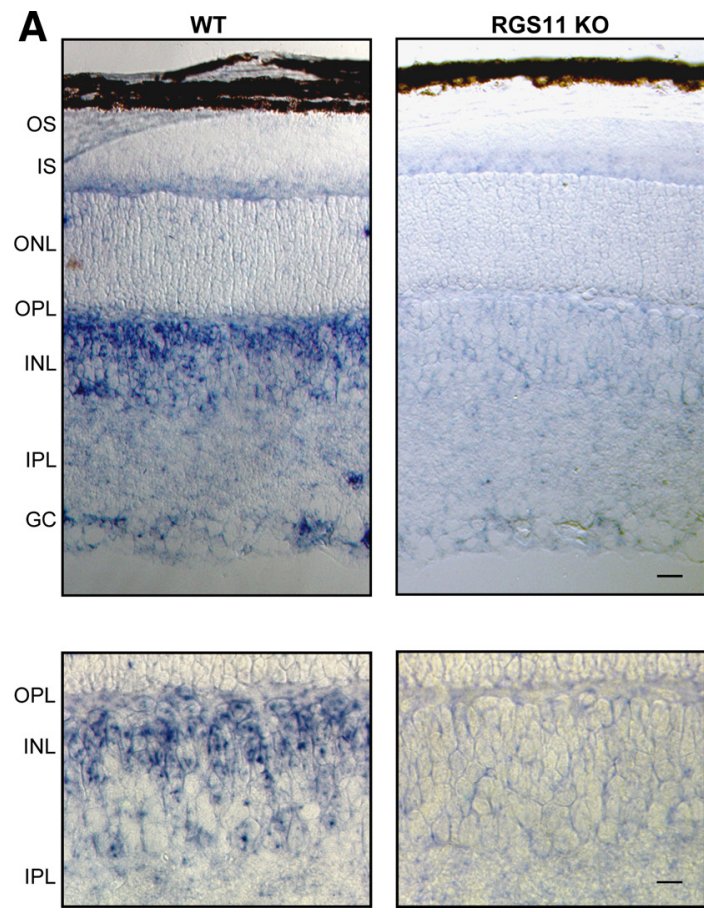

Figure 2. RGS11 is specifically expressed in 0N-bipolar cells. $\boldsymbol{A}$, In situ hybridizations using a riboprobe for RGS11 were performed on wild-type (WT) and RGS11 knock-out (RGS11 K0) retinas as described in Materials and Methods. Abbreviations are the same as in Figure 1. Scale bars: top, $20 \mu \mathrm{m}$; bottom, $10 \mu \mathrm{m}$. B, Colocalization of RGS11 (green) with marker protein (red) labeling: bipolar cells (PKC $\alpha$ ), horizontal cells (calbindin), photoreceptor presynaptic ribbon (CtBP2), and tips of ON-bipolar cell dendrites (mGluR6 and RGS7). Overlapping signals appear as yellow fluorescence in the combined channel (merge). Scale bar, $10 \mu \mathrm{m}$.

down two splice isoforms of $\mathrm{G} \beta 5, \mathrm{G} \beta 5 \mathrm{~L}$ and $\mathrm{G} \beta 5 \mathrm{~S}$, which have been reported to be expressed in the retina. Interestingly, immunoprecipitation with RGS-specific antibodies revealed a striking isoform selectivity of RGS/R9AP complexes for binding to G $\beta 5$. Whereas RGS9-1/R9AP was bound only to the predominant G $\beta 5 \mathrm{~L}$ form, RGS11/R9AP could be found in complex only with $\mathrm{G} \beta 5 \mathrm{~S}$, despite its substantially lower abundance in the retina. In summary, these results indicate that the retinaspecific RGS protein, RGS11, exists in complex with G $\beta 5$ S and R9AP subunits and that the complex is localized at the first visual synapse, a site distinct from the established localization of homologous RGS9-1/G $\beta 5$ L/R9AP in the outer segments of photoreceptors.

\section{Postsynaptic expression of RGS11/G $\beta 5$ S/R9AP complex in ON-bipolar neurons}

An observation that RGS11 is associated exclusively with G $\beta 5$ S isoform, which is not found in complex with photoreceptorspecific RGS9-1, suggests that the RGS11/G $\beta 5$ S/R9AP complex is not present in photoreceptors but rather is expressed in cells that form synaptic connections with them. To address this possibility, we performed in situ hybridization using an RGS11-specific antisense riboprobe (Fig. 2 A). Hybridization with wild-type retinas produced robust signal confined to the inner nuclear layer. In contrast, no signal was detected when retinas from RGS11 knockout mice were used in the experiment (Fig. 2A) or when control sense riboprobe was used (data not shown). Occasional positive staining was also observed in the ganglion cell layer. However, no detectable reactivity was found in the outer nuclear layer, in which signal from genes expressed in photoreceptor cells would be expected. Close examination of the signal at the inner nuclear layer at higher magnification (Fig. $2 A$, bottom) revealed that most staining was found in the cells with nuclei adjacent to pho-
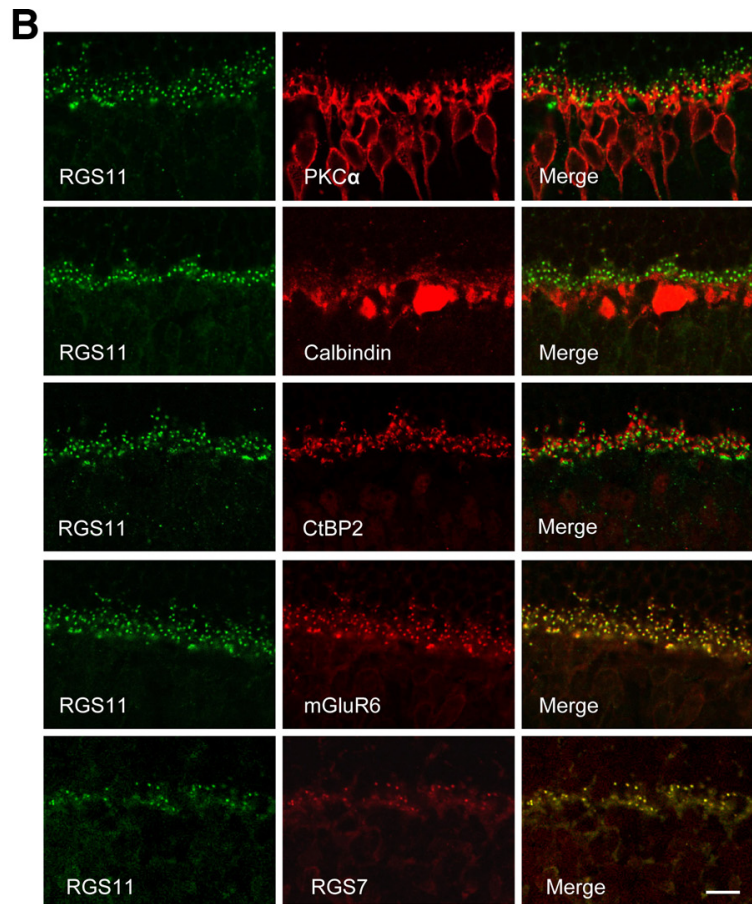

RGS1

toreceptor terminals, almost all of which were positive for RGS11. Because this region is typically occupied by various types of bipolar cells (Ghosh et al., 2004), we conclude that RGS11 is predominantly expressed in bipolar cells, postsynaptic to the photoreceptors.

To confirm postsynaptic localization of the RGS11 complex, we performed immunohistochemical colocalization studies. The results presented in Figure $2 B$ reveal that RGS11 puncta are found at the distal ends of the horizontal (calbindin positive) and bipolar cell (PKC $\alpha$ positive) dendrites, mapping more closely to the dendritic tips of the bipolar neurons. Consistent with the in situ hybridization results, RGS11 did not colocalize with the presynaptic marker CtBP2 (Schmitz et al., 2000) that labels ribbons in the photoreceptor axonal terminals. At the same time, RGS11 exhibited nearly perfect overlap with mGluR6 and RGS7 proteins that are specifically enriched at the dendritic tips of ON-bipolar cells (Vardi et al., 2002; Morgans et al., 2007; Cao et al., 2008). In summary, these results establish the postsynaptic localization of RGS11/G 35 S/R9AP complex at the dendritic tips of ON-bipolar neurons.

\section{All subunits of the RGS11/G $\beta 5$ S/R9AP complex contribute to its postsynaptic accumulation}

We used mouse knock-out strains lacking individual subunits of the RGS11/G $\beta 5$ S/R9AP complex to characterize their contribution to establishing postsynaptic localization (Fig. $3 A$ ). Immunostaining for the mGluR6 protein revealed preservation of the synaptic enrichment of this receptor at the tips of ON-bipolar cells in the retinas of all knock-out strains, indicating that organization of the postsynaptic compartment remains intact during elimination of the RGS11/G $\beta 5$ S/R9AP complex. Similarly, elimination of RGS11 or R9AP did not affect synaptic targeting of RGS7, another R7 RGS protein specifically enriched in the den- 
A

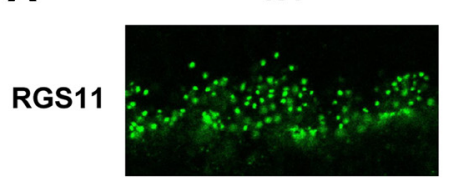

G $\beta 5$

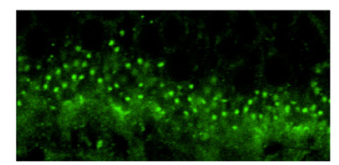

R9AP

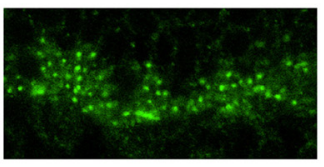

RGS7
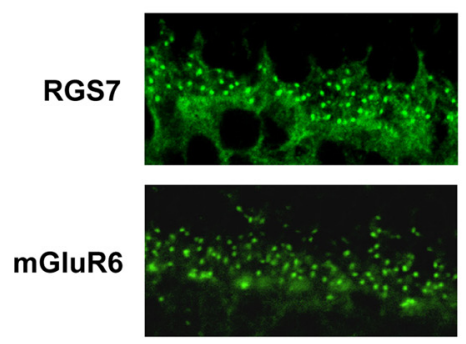

R9AP KO
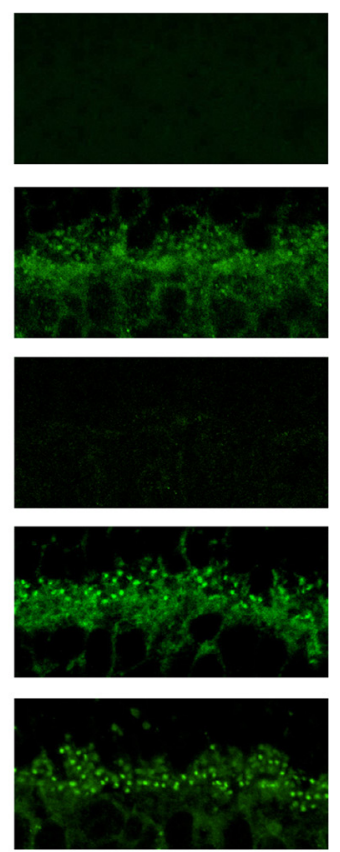

RGS11 KO
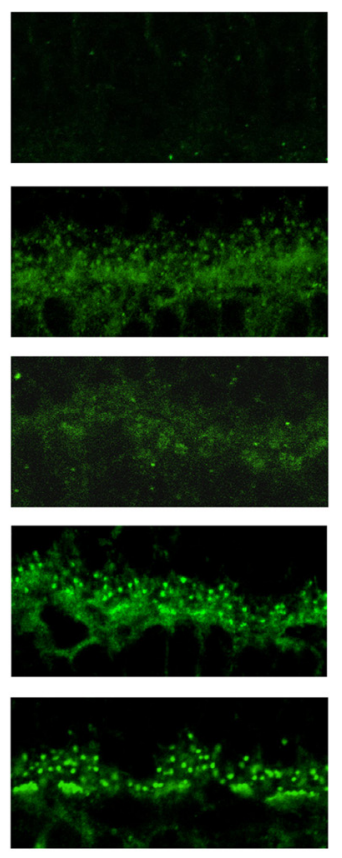

G $\beta 5$ KO
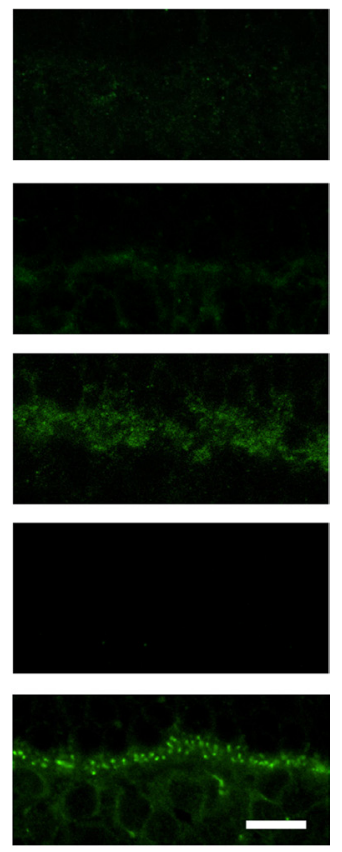

B
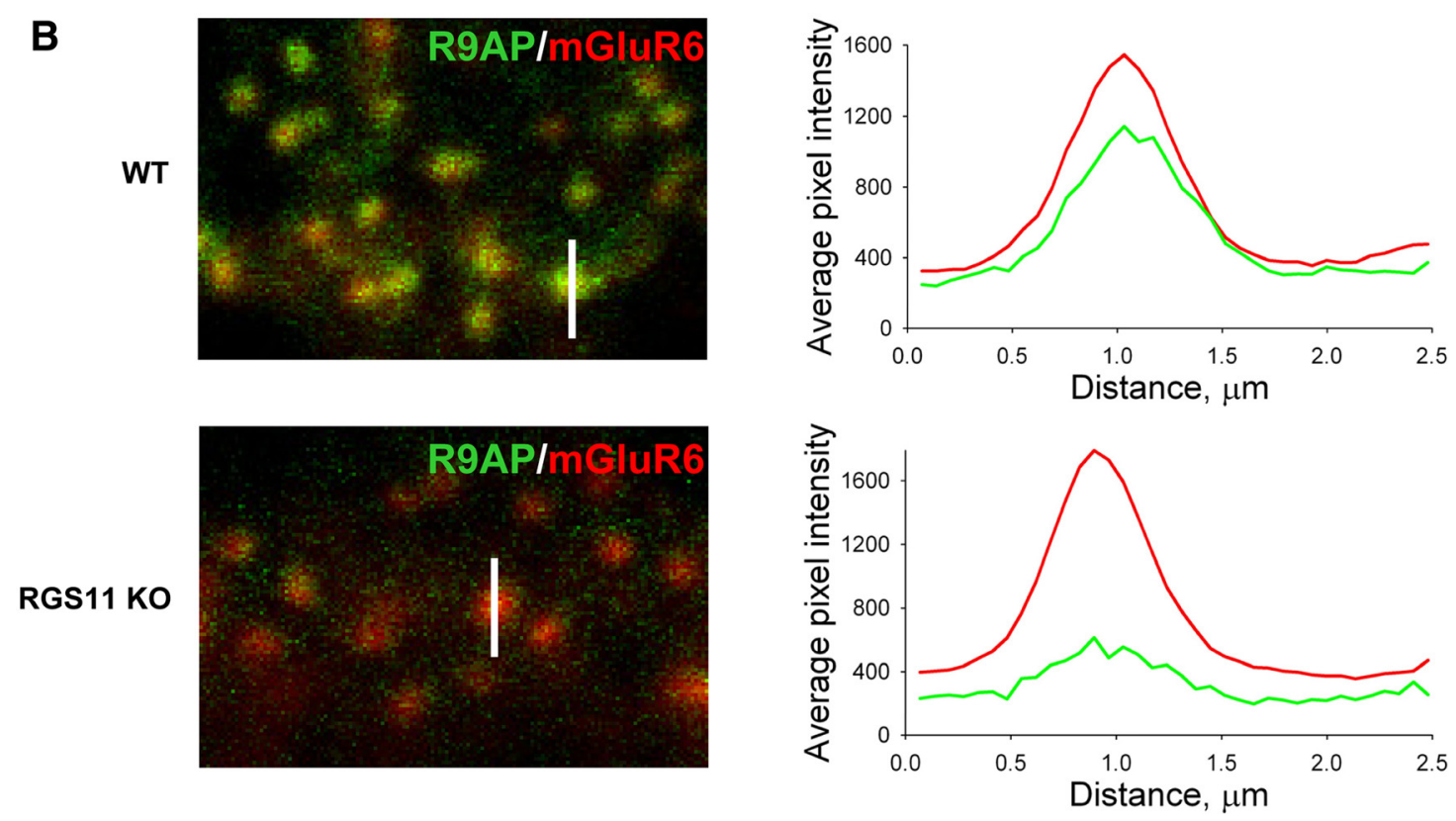

Figure 3. Contributions of individual subunits of RGS11/G $\beta 5 S / R 9 A P$ complex to its synaptic accumulation. $A$, Immunohistochemical analysis of RGS11, G $\beta 5$, and R9AP localization in the outer plexiform layer of the retinas from mice with targeted disruption of $\mathrm{RGS11}, G \beta 5$, and R9AP genes. Localization of mGluR6 and RGS7 proteins served as control reference points. Tissue processing and imaging was performed as described in Materials and Methods. Scale bar, $10 \mu \mathrm{m}$. B. Analysis of the R9AP immunofluorescence distribution in the outer plexiform layers of wild-type (WT) and RGS11 knock-out (KO) retinas. Retinas were double stained for mGluR6 (red) and R9AP (green), imaged, and processed by MetaMorph software. A line of 2.48 $\mu \mathrm{m}$ (white bar) was drawn through the center of the distinct mGluR6-positive synapses, and the distribution of the fluorescence intensity along this line was scanned to generate profiles shown to the right, in which red traces correspond to mGluR6 fluorescence and green to R9AP. Shown traces are average of 10 intensity scans within a single section. Parameters of the fluorescence peaks across multiple sections from several mice are presented in supplemental Table 1 (available at www.jneurosci.org as supplemental material).

drites of ON-bipolar cells (Morgans et al., 2007; Cao et al., 2008). No RGS11-positive immunofluorescence was detected in retinas of RGS11, R9AP, and G $\beta 5$ knock-outs, consistent with the loss of RGS11 protein in the retinas of these mice (Chen et al., 2003; Cao et al., 2008).

We found that both R9AP and RGS11 knock-outs showed reduced intensity of $\mathrm{G} \beta 5$ staining in the outer plexiform layer (Fig. 3A) (supplemental Fig. 1, available at www.jneurosci.org as supplemental material). Quantification of the intensity and dis- tribution of the immunofluorescence revealed that reduction in G $\beta 5$ staining within the mGluR6-positive puncta was proportionate to the net decrease in the signal across the outer plexiform layer (supplemental Table 1, available at www.jneurosci.org as supplemental material). This observation indicates for the unaltered accumulation of $\mathrm{G} \beta 5$ at the dendritic tips that is likely explained by the preservation of RGS7/G $\beta 5$ accumulation concurrent with the loss of the RGS11/G $\beta 5$ S complexes at the same sites. 


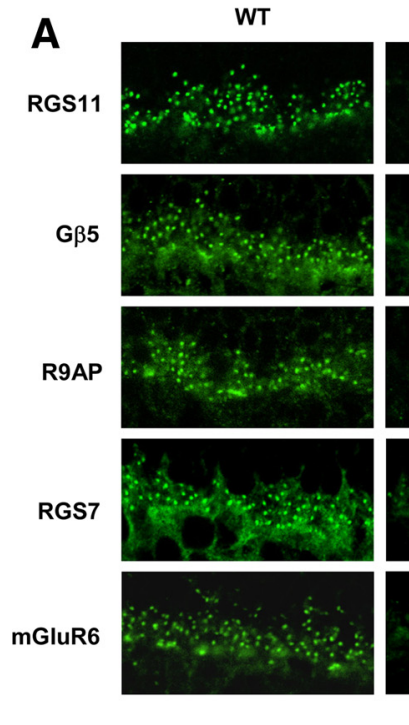

C

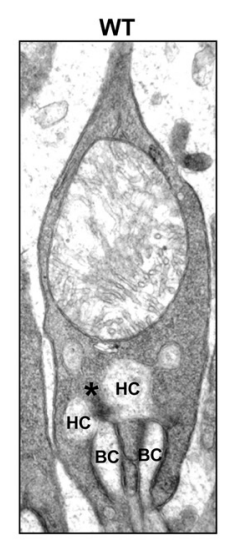

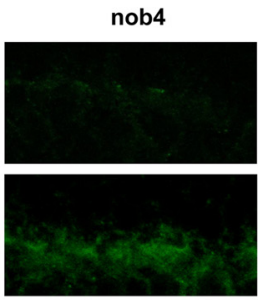
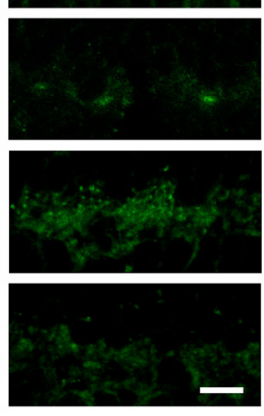

Nob4

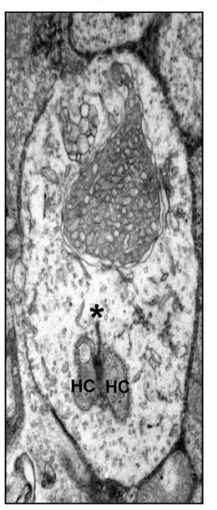

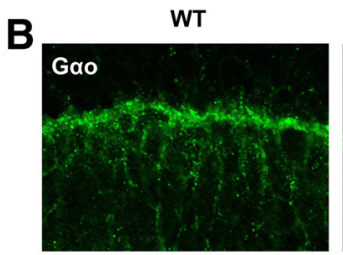
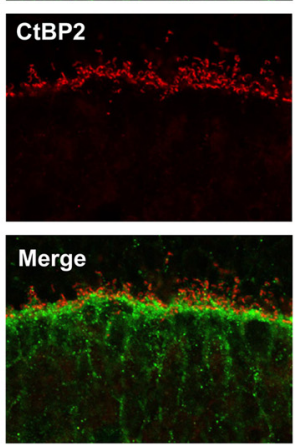

Triads containing ON-bipolar dendrites Triads lacking ON-bipolar dendrites

\section{CtBP2}
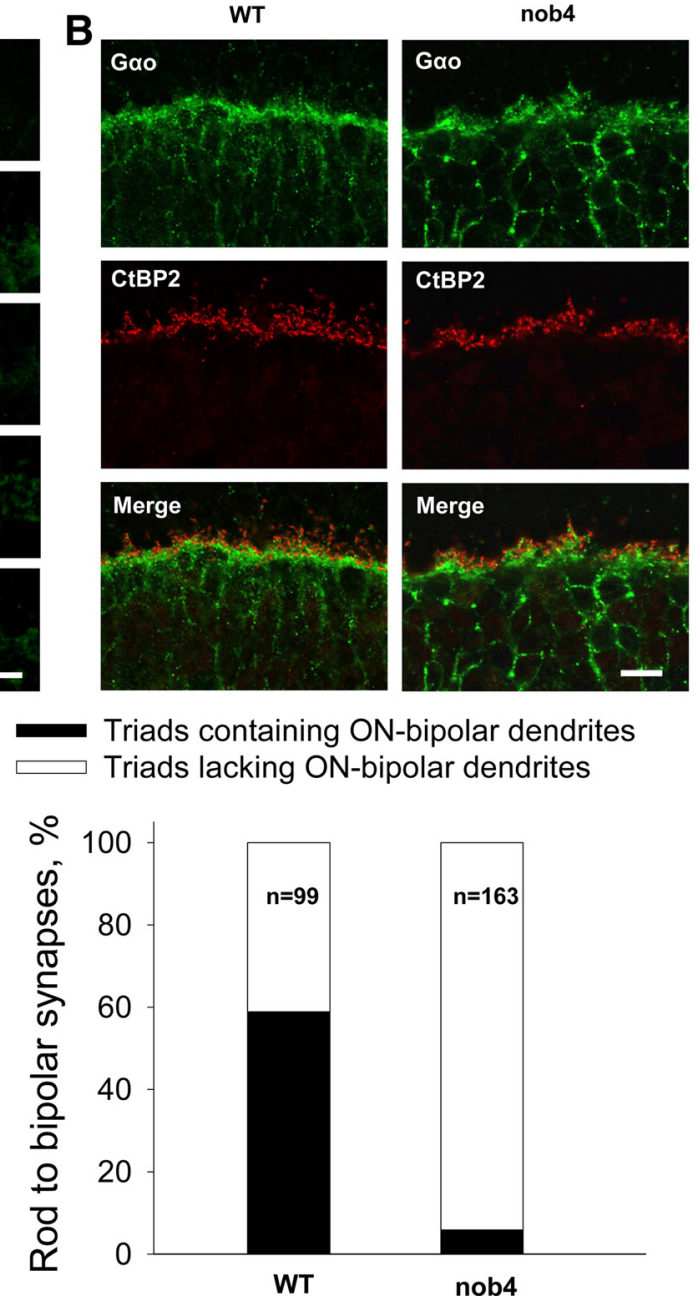

Figure 4. Mutations in mGluR6 prevent synaptic integration of ON-bipolar dendrites and abolish postsynaptic accumulation of RGS11/G $\beta 5 S / R 9 A P$. A, Immunohistochemical analysis of protein localization at outer plexiform layer of nob4 mice. Indicated proteins were immunostained by specific antibodies. Retinas of wild-type (WT) and nob4 mice were processed simultaneously, and images were acquired with the same exposure settings. Scale bar, $10 \mu \mathrm{m} . \boldsymbol{B}$, Immunohistochemical analysis of the presynaptic (CtBP2) and postsynaptic (G $\left.\alpha_{0}\right)$ marker apposition in the retinas of wild-type and nob4 mice. Scale bar, $10 \mu \mathrm{m}$. C, Comparison of the morphology of synapses between rods and horizontal/bipolar cells by electron microscopy. High magnification of the synapses of wild-type and nob4 retinas reveals the absence of the bipolar cell $(\mathrm{BC})$ dendrites from the rod terminals that at the same time contained intact ribbon $\left({ }^{*}\right)$ and horizontal cell dendrites $(\mathrm{HC})$. Right, Quantification of synapses with all three identifiable features. Quantification results are based on preparations obtained from two separate mice for each genotype. The numbers of the counted synaptic triads in which both horizontal cell dendrites and ribbons were identified are reported on the graph.

Remarkably, knock-out of RGS11 or G $\beta 5$ abolished postsynaptic localization of R9AP. In contrast to the concentration of discrete puncta at the dendritic tips of the wild-type ON-bipolar cells, in RGS11 and G $\beta 5$ knock-out retinas, accumulation of R9AP in the mGluR6-positive puncta (Fig. 3B) (supplemental Table 1, available at www.jneurosci.org as supplemental material) was dramatically reduced (approximately fourfold to fivefold), suggesting that the localization of R9AP requires association with RGS11/G $\beta 5 S$. Total immunofluorescence intensity of the R9AP staining in the outer plexiform layer was unaltered in G $\beta 5$ knock-outs and only modestly reduced in RGS11 knock-out retinas (supplemental Fig. 1, available at www.jneurosci.org as supplemental material), suggesting that displacement of R9AP from the dendritic tips has little effect on its expression level.

The loss of R9AP targeting to the dendritic tips of ON-bipolar cells as a result of elimination of RGS11/G $\beta 5$ S complex differs from findings in the photoreceptor cells, in which targeting of R9AP to the outer segments occurred independently from its association with its binding partner RGS9-1/G $\beta 5 \mathrm{~L}$ (Martemyanov et al., 2003; Baker et al., 2008). We therefore addressed a possibility that elimination of RGS11 or G $\beta 5$ could indirectly but universally affect the ability of R9AP protein to localize normally. Examination of R9AP staining in photoreceptors of RGS11 and G $\beta 5$ knock-out mice revealed that the majority of the immunofluorescence is confined to the outer segments (supplemental Fig. 2, available at www.jneurosci.org as supplemental material). This indicates that, unlike in photoreceptors, postsynaptic targeting of R9AP in ON-bipolar cells requires formation of a complex with RGS11 and G $\beta 5$, making association between all three subunits a prerequisite for the efficient delivery to the dendritic tips.

\section{Targeting of RGS11/G $\beta 5$ S/R9AP complexes in bipolar cells} requires its association with mGluR6

The finding that disruption of any subunit of RGS11/G $\beta 5$ S/R9AP complex affected its postsynaptic targeting but did not alter the targeting of the main postsynaptic signaling molecule, mGluR6, prompted us to evaluate the contribution of the functional receptor to establishing postsynaptic localization of the RGS11/G $\beta 5 \mathrm{~S} /$ R9AP. For this purpose, we studied nob4 mice, which carry a 
point mutation in the mGluR6 gene, previously reported to lead to a lack of detectable mGluR6 at the dendritic tips of the bipolar cells (Pinto et al., 2007). In agreement with the previous report (Morgans et al., 2007), we found no RGS11-positive synaptic puncta in the outer plexiform layer of nob4 retinas (Fig. $4 \mathrm{~A}$ ). Furthermore, postsynaptic localization of G $\beta 5$ and R9AP was severely disrupted and showed no characteristic puncta (Fig. $4 A)$. Although the intensity of the RGS7positive puncta was substantially reduced, some RGS7 was still found at the dendritic tips.

One possibility for the lack of RGS11/ $\mathrm{G} \beta 5 \mathrm{~S} / \mathrm{R} 9 \mathrm{AP}$ in the dendritic tips of the nob4 ON-bipolar cells is their failure to establish a proper postsynaptic compartment and thus to establish a proper synapse. Although the overall architecture of nob4 retinas was found previously to be normal (Pinto et al., 2007), fine morphology of the synaptic connections in the outer plexiform layer was not examined for any loss-of-function mGluR6 mutants. Consistent with the normal morphology, we found that, in nob4 retinas, the ON-bipolar-specific G-protein $\mathrm{G} \alpha$ o was concentrated in dendrites in precise apposition to photoreceptor terminals, in a pattern indistinguishable from the wildtype retinas (Fig. 4B). However, close examination of the rod to ON-bipolar synapses at high resolution by transmission electron microscopy revealed failure of the ON-bipolar dendrites to reach into the invaginating rod terminals. At the same time, synaptic connections of the horizontal cells to rod terminals were unaltered (Fig. 4C). Quantification of the electron microscopy data showed severe reduction in a number of correctly formed synaptic triads between wild-type and nob4 retinas (Fig. 4C). Because these deficiencies are observed in combination with the apparently normal dendritic morphology (as revealed by $\mathrm{PKC} \alpha$ and $\mathrm{G} \alpha$ o staining), we conclude that the ON-bipolar dendrites fail to invade photoreceptor terminals but display normal proliferation.

To test the possibility that RGS11/ G $\beta 5$ S/R9AP is targeted to the dendritic tips via a direct interaction with mGluR6 we co-expressed mGluR6 with components of the RGS11 complex in mammalian HEK293 cells. The results presented in Figure 5 demonstrate that RGS11/G 35 S can efficiently bind to mGluR6 and the complex can be purified by immunoprecipitation. We also found that cotransfection with R9AP did not affect the ability of RGS11/ $\mathrm{G} \beta 5 \mathrm{~S}$ to form a complex with mGluR6, once again arguing that targeting determinants of the complex are located within RGS11/G $\beta 5$ S.

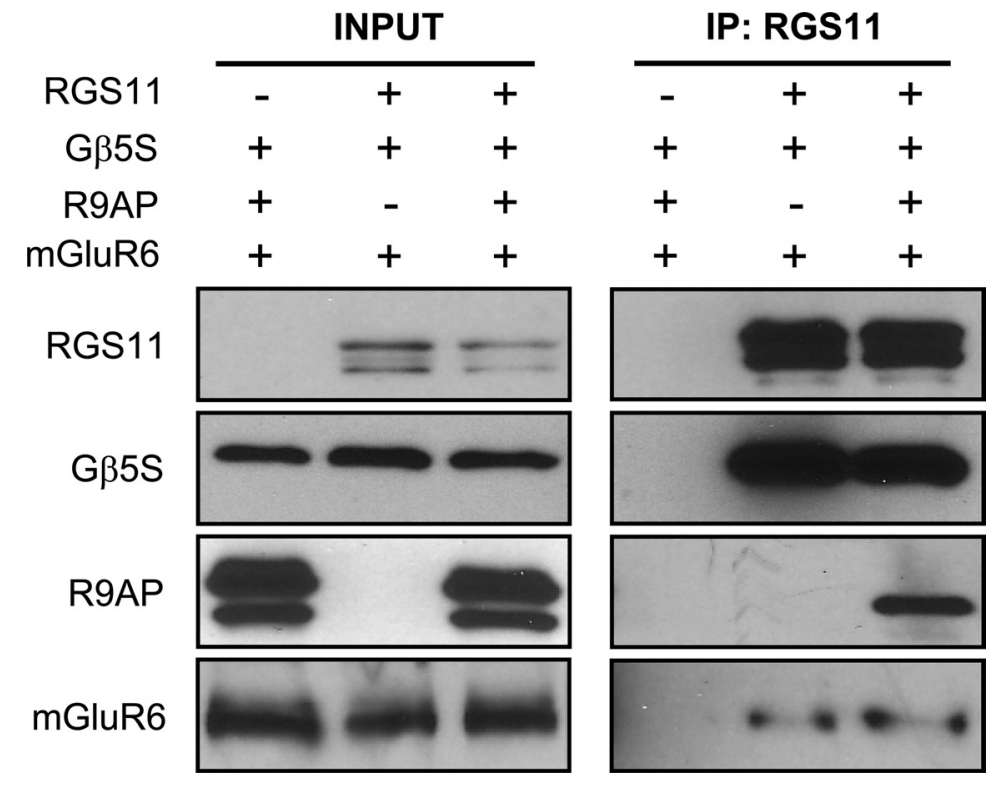

Figure 5. Coimmunoprecipitation of mGluR6 with RGS11/G $\beta 5 S / R 9 A P$ complex. HEK293T cells were transfected with the indicated constructs and $48 \mathrm{~h}$ later were lysed in a buffer containing $0.5 \%$ of $n$-dodecanoylsucrose. RGS11 antibodies were used for immunoprecipitation (IP) as described in Materials and Methods. Eluted proteins were detected by Western blotting using specific antibodies. Cells expressing all of the constructs except RGS11 served as a control for the nonspecific binding.

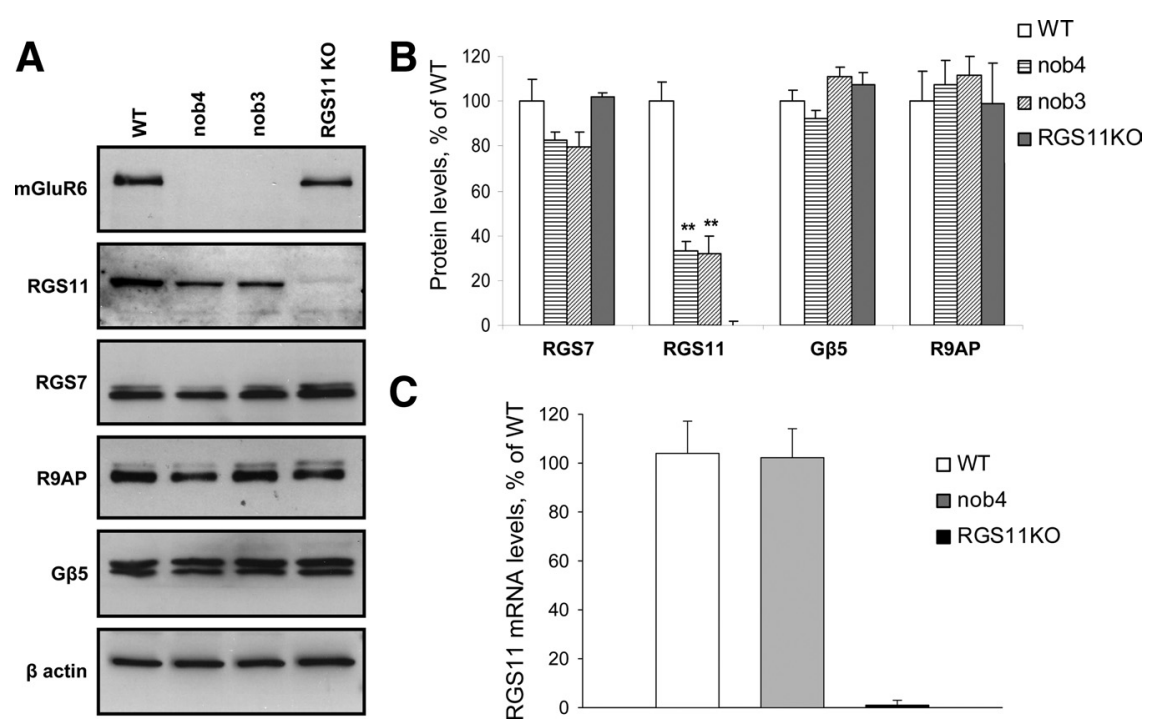

Figure 6. Elimination of mGluR6 specifically reduces RGS11 expression at the posttranscriptional level. $\boldsymbol{A}$, Western blot analysis of protein expression in the retinas of wild-type (WT), nob3, and nob4 mice. Total retina lysates $(8.5 \mu \mathrm{g})$ were loaded in each lane. Blots were probed with indicated antibodies as described in Materials and Methods. B, Quantification of the Western blotting data. Band densities of indicated proteins were determined by NIH ImageJ software and normalized to levels of $\beta$-actin present in the same sample. Samples from three to eight retinas were used in the analysis. Error bars are SEM values. ${ }^{* *} p<0.01$. C, Quantitative RT-PCR determination of RGS11 mRNA levels. Relative level of RGS11 mRNAs was measured by quantitative RT-PCR and normalized to the level of $\beta$-actin mRNA amplified in parallel as an endogenous reference. Relative quantification algorithm was used in which changes in amplification threshold were normalized to sample from wild-type mice. Data are averaged from three separate groups of animals. KO, Knock-out.

Observation that RGS11/G $\beta 5$ S/R9AP physically associates with mGluR6 prompted us to determine the effects of mGluR6 on the expression of RGS11. In these studies, in addition to retinas from the nob4 mutant, we used retinas of nob3 mice that contain a nonsense mutation early in the sequence of the mGluR6 gene, essentially eliminating translation of functional mGluR6 protein (Maddox et al., 2008). Western blot analysis (Fig. 6A) reveals that both nob3 and nob4 retinas lack detectable expression 

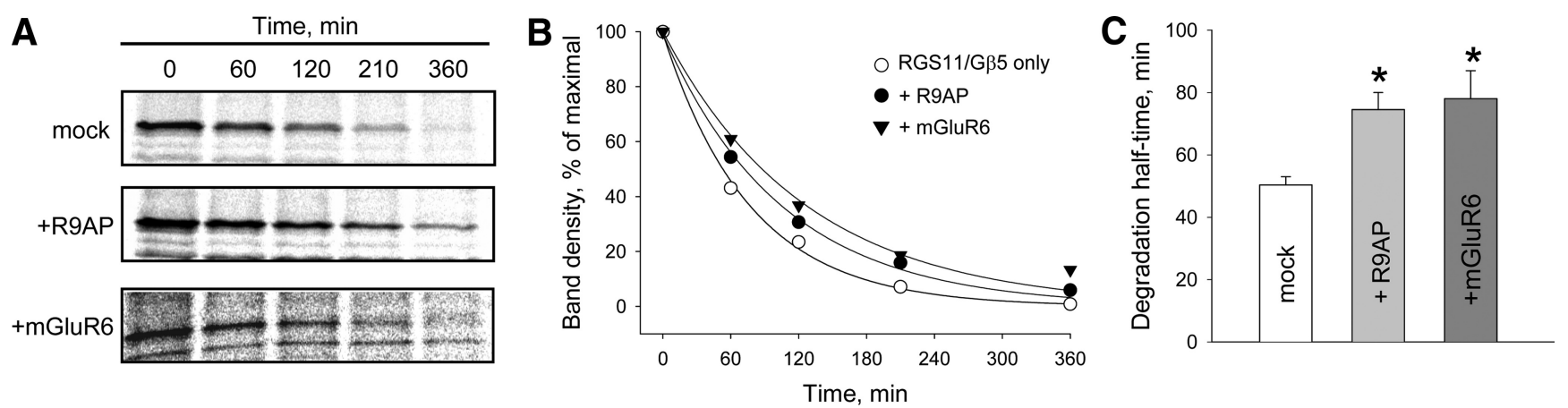

Figure 7. R9AP and mGluR6 contribute to the proteolytic stability of RGS11/G $\beta 5 S$. A, Pulse-chase labeling of RGS11. NG108-15 cells transiently transfected with RGS11, G $\beta 55$ with or without R9AP, or mGluR6. Cells were labeled by ${ }^{35} \mathrm{SMet} /$ Cys as described in Materials and Methods. The label was removed and replaced with fresh media containing nonradioactive amino acids. Cells were collected at the indicated time points during the chase and frozen in liquid nitrogen. After disruption of the cells, RGS11 was immunoprecipitated using specific antibodies and resolved on an SDS-PAGE gel. The gel was subjected to autoradiography to reveal the radiolabeled RGS11. B, Left, Time course of RGS11/G $\beta 5 S$ degradation. Intensities of radioactive bands were quantified using ImageQuant software and plotted as a function of time. The experimental points were fitted by single exponents. The data presented in the figure are representative of two or three independently conducted experiments. C, Comparison of the RGS11/G $\beta 5 S$ degradation half-time in the absence or presence of R9AP and mGluR6. The values were derived from single-exponential analysis of the degradation time course $(\boldsymbol{B})$. Error bars represent SEM values. ${ }^{*} p<0.05$.

of mGluR6 protein, indicating that these mice are essentially null mutants. Remarkably, the elimination of mGluR6 resulted in a threefold to fourfold reduction in the levels of RGS11 protein. This reduction was specific for RGS11. Although we did find that levels of RGS7 were reduced by $\sim 20 \%$, this reduction was not statistically significant (Fig. 6B). Because RGS7 is found at several locations in the retina, we have further examined whether nob4 mutation could affect its expression only in outer plexiform layer of retinas. Quantification of the immunofluorescence staining intensities in the region confirmed robust reduction in RGS11 levels but again failed to provide evidence for appreciable change in RGS7 levels (supplemental Fig. 3, available at www.jneurosci.org as supplemental material). The reduction in RGS11 was not observed at the level of the messenger RNA as revealed by quantitative RT-PCR, arguing that the lack of protein expression is a posttranscriptional effect (Fig. 6C).

\section{R9AP and mGluR6 enhance proteolytic stability of RGS11/G $\beta 5 S$}

To examine the mechanisms responsible for the reduction of RGS11 expression observed in retinas lacking R9AP or mGluR6, we evaluated the susceptibility of RGS11/G $\beta 5$ S to proteolytic degradation. This was achieved by measuring the lifetime of the complex by pulse-chase metabolic labeling in transfected NG108-15 cells. As illustrated in Figure 7, when RGS11 is coexpressed with $\mathrm{G} \beta 5$, it takes only $50 \pm 4 \mathrm{~min}$ to degrade half of the protein complex in the cells. This short lifetime of the RGS11/ $\mathrm{G} \beta 5 \mathrm{~S}$ in cells matches very closely reported degradation halftime of RGS9/G $\beta 5$ (59 \pm 6 ) (Anderson et al., 2007a), a protein complex that has been shown to require association with R9AP for maintaining its proteolytic stability. Similarly to RGS9, we found that the stability of RGS11/G $\beta 5$ S complex could be enhanced by coexpression with R9AP (Fig. $4 A, B$ ), but the degree of the proteolytic protection conferred by R9AP was less in case of the RGS11 (Anderson et al., 2007a). Furthermore, coexpression with mGluR6 also prolonged lifetime of the RGS11/G $\beta 5 S$ complex in the cells, providing additional evidence for their direct interaction (Fig. 7). In addition, these findings establish the distinct contributions of RGS11 and R9AP subunits in providing the accumulation of the complex at the tips of the ON-bipolar dendrites (reported in Fig. 3). Although R9AP serves to stabilize the complex, it does not carry targeting determinants, relying on
RGS11/G $\beta 5$ S for the localization to the dendritic tips of ONbipolar cells.

\section{Reduction of the $\mathrm{G} \alpha_{\mathrm{o}}$ deactivation by RGS11 elimination is not sufficient for altering kinetics of bipolar cell responses to light}

The observation that RGS11/G $\beta 5$ S/R9AP is localized to the dendritic tips of ON-bipolar cells in which it interacts with the mGluR6 makes this complex uniquely positioned to serve as a regulator of the ON-bipolar cell responses to light, mediated by the mGluR6 cascade. Because the G-protein $\mathrm{G} \alpha_{\mathrm{o}}$ is an established signaling intermediate of the mGluR6 signaling, we started by evaluating the catalytic properties of RGS11/G $\beta 5$ S in stimulating the GTPase activity of $\mathrm{G} \alpha_{\mathrm{o}}$ (Fig. 8). We used a single turnover system with purified recombinant components to study selectively the GTP hydrolysis step dissociated from receptor effects. As noted previously (Hooks et al., 2003), we found RGS11/G $\beta 5 S$ to be a very effective GAP for $\mathrm{G} \alpha$, which at a $1 \mu \mathrm{M}$ concentration, was capable of accelerating the GTP hydrolysis rate by approximately one order of magnitude (Fig. 8). This was substantially greater than the ability of RGS9-1/G $\beta 5 \mathrm{~L}$, a main photoreceptor GAP, which under identical conditions stimulated $\mathrm{G} \alpha$ o GTPase by only $\sim 1.5$-fold. However, the GAP activity of RGS11/G $\beta 5 S$ was half that of RGS7/G $\beta 5$ S, another RGS protein enriched in the ON-bipolar cell dendrites.

To determine the contribution of RGS11 complex to the light response of ON-bipolar neurons, we performed whole-cell voltage-clamp recordings from rod ON-bipolar cells. Figure $9 \mathrm{~A}$ shows response families in dark-adapted retinas to brief flashes of light of increasing strength, which look broadly similar between wild-type and RGS11 knock-out cells. Both the relationship between the flash strength and response amplitude (Fig. 9C) and the amplitude and time course of the derived average response per photon (Fig. 9B) showed no difference between the two. To examine the possibility that RGS11-dependent GAP activity was most prominent in background light, we measured families of flash responses superimposed on a background light that generated $100 \mathrm{R} * / \mathrm{s} / \operatorname{rod}$ (Fig. $9 A$ ). Just as for the dark-adapted cells, background light did not influence the time course or amplitude of the average response per photon (Fig. 9B) and also did not affect light adaptation. The gain of signaling in background light (Fig. 9D) was not changed in RGS11 knock-out rod bipolar cells. 
These results suggest that the elimination of RGS11 did not diminish the GAP activity toward $\mathrm{G} \alpha_{\mathrm{o}}$ and thus did not influence the magnitude of time course of rod ONbipolar cell responses.

\section{Discussion}

In this study, we establish that RGS11 is an RGS protein exclusively expressed in the bipolar cells of the retina in which it forms an obligatory complex with two of its subunits: the short splice isoform of $G \beta 5$, G $\beta 5$ S, and R9AP. This specific subunit composition of the complex raises several fascinating points. First, despite the higher abundance of alternatively spliced G $\beta 5 \mathrm{~L}$, RGS11 binds exclusively to the sparser $\mathrm{G} \beta 5 \mathrm{~S}$, demonstrating a clear segregation of $\mathrm{G} \beta 5$ splice isoforms to different types of cells. This is supported by the observation that photoreceptor-specific RGS9-1 instead interacts exclusively with G $\beta 5 \mathrm{~L}$ (Fig. 1) (see also Makino et al., 1999; $\mathrm{Hu}$ and Wensel, 2002) and that G $\beta 5$ S and G $\beta 5 L$ show distinct localization profiles across retinal layers (Song et al., 2007). In combination with the postsynaptic localization of RGS11 in the ON-bipolar neurons, these findings suggest that $\mathrm{G} \beta 5 \mathrm{~S}$, but not $\mathrm{G} \beta 5 \mathrm{~L}$, is the ONbipolar-specific splice isoform of $\mathrm{G} \beta 5$. Second, these results unexpectedly reveal that R9AP is also expressed outside of the photoreceptors. In mammalian retina, R9AP expression was reported previously to be present only in the outer segments of photoreceptors in which it was found associated with RGS9-1/G $\beta 5 \mathrm{~L}$ (Hu and Wensel, 2002; Keresztes et al., 2003; Song et al., 2007), although low levels of R9AP mRNA were also detected in several nervous system structures (Keresztes et al., 2003). Thus, the present study establishes a second location of R9AP expression, the dendritic tips of the ON-bipolar cells. Third, R9AP appears to be the major membrane anchor of RGS11/G $\beta 5 S$ in the bipolar cells because knock-out of R9AP results in essentially complete loss of RGS11 (Fig. 3) (Cao et al., 2008). It appears that, despite the demonstrations that RGS11 can be immunoprecipitated with readily detectable levels of R7BP (Song et al., 2007) and that R7BP is also found at the dendritic tips of the ONbipolar cells (Cao et al., 2008), this interaction does not substantially contribute to RGS11 proteolytic stabilization. Because the binding of R7BP and R9AP with R7 RGS proteins is mutually exclusive, it is possible that competition with R7BP could serve to attenuate the levels of dendritic RGS11. Alternatively, it seems equally plausible that the expression level of R7BP is significantly lower than that of R9AP. This in combination with the ability of knock-out cells (open).
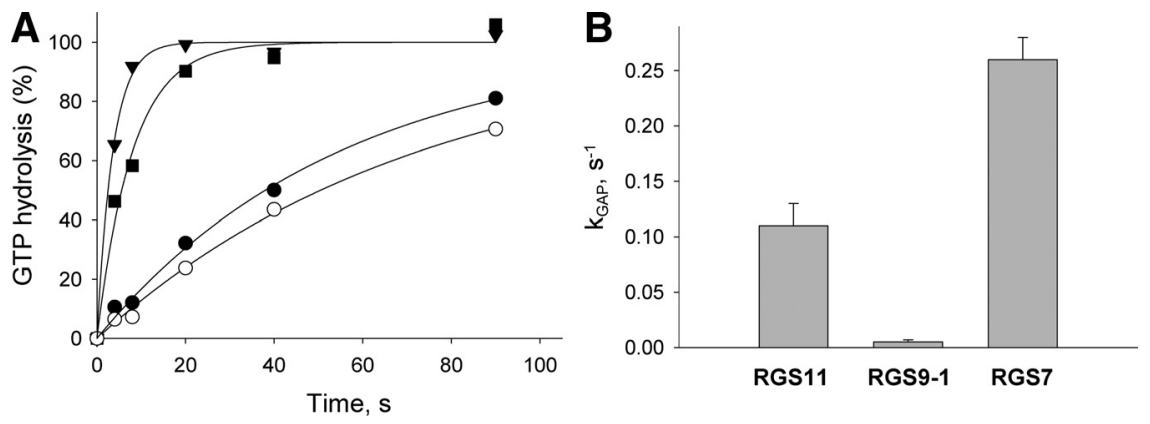

Figure 8. Analysis of the RGS11/G $\beta 5 S$ GAP activity. $A$, Time courses of the GTP hydrolysis on $G \alpha_{0}$, in the absence of RGS proteins $(\bigcirc)$ or in the presence of RGS11/G $\beta 5 S(\boldsymbol{\square}), \operatorname{RGS7/G} \beta 5 S(\boldsymbol{\nabla})$, or RGS9-1/G $\beta 5 \mathrm{~L}$ and PDE $\gamma(\mathbf{O})$. Individual time points were normalized to maximal GTP hydrolysis and plotted as a function of time. Data were fitted with single exponent that was used to determine the rate constant of the reaction. The experiment shown is representative of three experiments yielding similar results. $B, k_{\mathrm{GAP}}$ values were calculated by subtracting the basal unstimulated rate constant of GTP hydrolysis from the RGS-stimulated rates. Errors bars are SEM values.

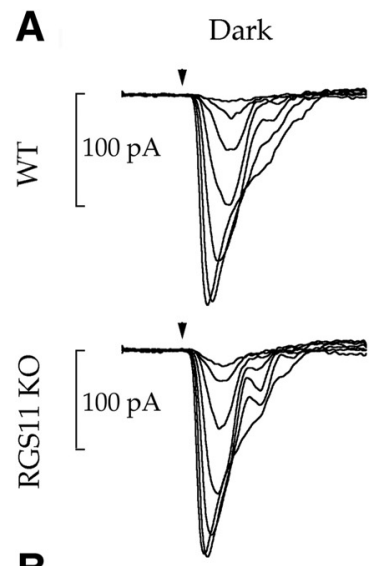

B

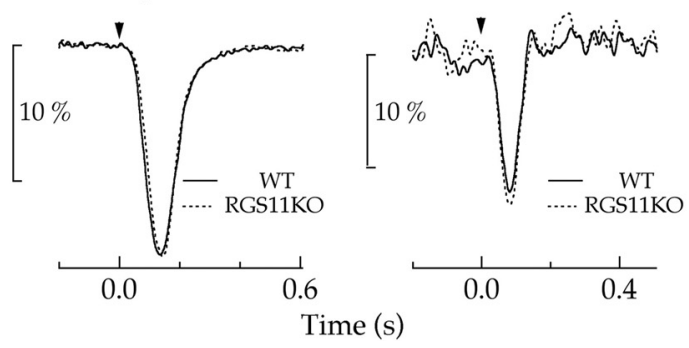

C
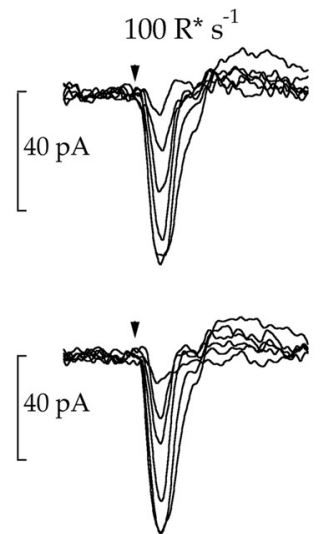

D

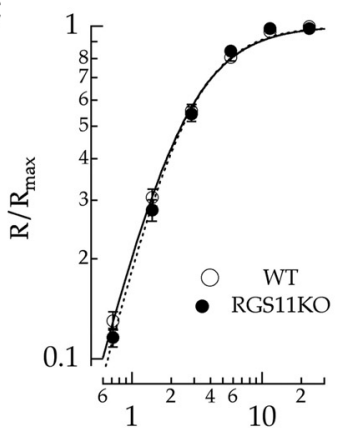

Flash Strength $\left(\mathrm{Rh}^{*} / \mathrm{rod}\right)$

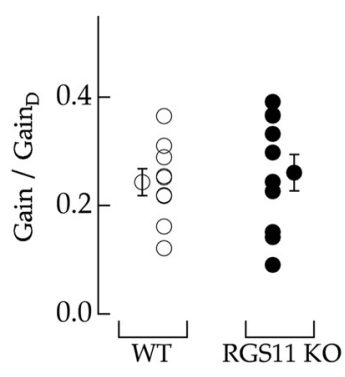

Figure 9. Light responses of rod bipolar cells in RGS11 knock-out mice. A, Light-evoked inward currents in dark-adapted rod bipolar cells were plotted as a function of time for brief flashes (arrow) of $0.38,0.76,1.5,3.1,6.1,12$, and $24 \mathrm{Rh}^{*} / \mathrm{rod}_{\text {, }}$ and in light-adapted (100 R*/s/rod) cells for briefflashes (arrow) of 1.1,2.3, 4.6,9.2, 18, and 37 Rh*/rod. The bandwidth was $50 \mathrm{~Hz}$. B, The estimated responses per photon plotted as a percentage of maximum inward current for dark-adapted and light-adapted cells. The dark-adapted wild-type (WT) response (solid) was the average of 547 responses from $5-25 \%$ of the saturating response (Sampath et al., 2005) across 23 rod bipolar cells. The dark-adapted RGS11 knock-out (KO) response (dotted) was the average of 570 responses across 22 rod bipolar cells. The light-adapted wild-type response (solid) was the average of 130 responses from 5-35\% of the saturating response across nine rod bipolar cells. The light-adapted RGS11 knock-out response (dotted) was the average of 140 responses across nine rod bipolar cells. $C$, Response-intensity relationship across all dark-adapted rod bipolar cells in wild-type $(n=23)$ and RGS11 knock-out $(n=22)$ mice. Data were plotted as a mean \pm SD, and the least-squares Hill curve fits to the mean and SDs are superimposed. For wild-type rod bipolar cells, $I_{1 / 2}=2.4 \mathrm{Rh}^{*} /$ rod, and $n=1.58$ (solid). For RGS11 knock-out rod bipolar cells, $I_{1 / 2}=2.5 \mathrm{Rh} * / \mathrm{rod}$, and $n=1.66$ (dotted). The difference in these fit parameters is not statistically significant. $\boldsymbol{D}$, Gain changes in background light ( $100 \mathrm{R}^{*} / \mathrm{rod} / \mathrm{s}$ ) were calculated and plotted for individual rod bipolar cells as in the study of Dunn et al. (2006). Gain normalized to gain in darkness was $0.24 \pm 0.07(n=9)$ for wild-type cells (filled) and $0.26 \pm 0.10(n=9)$ for RGS11

R7BP to interact with RGS7 (Drenan et al., 2005; Martemyanov et al., 2005; Song et al., 2007) might result in the insufficient levels of this membrane anchor to substitute for the loss of R9AP. Altogether, these results provide evidence for the formation of a unique RGS11/ G $\beta 5$ S/R9AP complex at the dendritic tips of the ON-bipolar neurons. 
Our results suggest the constitutive protein-protein interactions in RGS11/G $\beta 5 S / R 9 A P$ complex, making it an obligate heterotrimer. Indeed, we demonstrate that posttranslational stabilization of RGS11 required association not only with G $\beta 5$ but also with R9AP, which serves to additionally protect the complex from proteolytic degradation. This is similar to the constitutive interactions in RGS9-1/G $\beta 5$ L/R9AP (Keresztes et al., 2004) and RGS9-2/G $\beta 5$ S/R7BP (Anderson et al., 2007b) complexes, in which association with membrane anchors R9AP and R7BP serves to shield specific degradation determinants located at the $\mathrm{N}$ terminus of the RGS9 (Anderson et al., 2007b). It is interesting to note that the degree of proteolytic protection provided by either R9AP or R7BP for RGS9 isoforms ( $\sim 5$-fold) (Anderson et al., 2007a) appears to be greater than that provided to RGS11 by R9AP ( $\sim 1.5$-fold) (Fig. 4). This observation raises a possibility that RGS11 might contain additional instability determinants to require protein-protein interactions outside of the RGS11/ G $\beta 5$ S/R9AP complex formation to achieve high expression levels. One such additional contact is the association with the receptor mGluR6 that contributes to the proteolytic protection to RGS11.

The obligatory nature of subunit interactions within the RGS11/G $\beta 5$ S/R9AP complex requires all three genes to be coexpressed in the same cell to achieve a significant level of protein expression. Interestingly, ON-bipolar cells in the retina appear to be the only cells in the organism in which we could find this expression overlap. This might explain why, despite reported expression of RGS11 mRNA in the brain (Snow et al., 1998; Giudice et al., 2001), the presence of RGS11 protein was found only in the retina (Morgans et al., 2007; Rao et al., 2007; Song et al., 2007). Careful evaluation of tissue specificity of RGS11 expression with the polyclonal antibodies required the use of the RGS11 knockout mice to account for the nonspecific signals (Fig. 1). This stringent control also indicated that the RGS11 reactivity we observed previously in the brain using direct immunoblotting represents nonspecific cross-reactivity (Anderson et al., 2007b). Although stability of RGS11/G $\beta 5$ S requires coexpression with R9AP, R9AP itself appears to be a stable protein, suggesting that transcriptional control of its expression likely serves as a limiting factor regulating the expression of RGS11 protein.

In contrast to the conservation of its role in mediating proteolytic stabilization of both RGS9-1/G $\beta 5 \mathrm{~L}$ and RGS11/ $\mathrm{G} \beta 5 \mathrm{~S}$, the contribution of R9AP in mediating subcellular targeting of RGS complexes differs. In photoreceptors, R9AP is efficiently delivered to the outer segment compartment $(\mathrm{Hu}$ and Wensel, 2002; Martemyanov et al., 2003). This targeting occurs via the "default pathway," requiring only the presence of the C-terminal transmembrane region (Baker et al., 2008), and does not depend on the association with RGS9-1/G $\beta 5 \mathrm{~L}$ (Martemyanov et al., 2003). In turn, targeting of RGS9-1/ $\mathrm{G} \beta 5 \mathrm{~L}$ is dependent on R9AP, and, in the absence of complex formation with R9AP, RGS9-1/G $\beta 5 \mathrm{~L}$ is excluded from the outer segments (Martemyanov et al., 2003). However, in ONbipolar cells, targeting of R9AP to the dendritic tips requires its association with RGS11/G $\beta 5 S$, suggesting that the targeting signal instead is localized on the RGS11/G $\beta 5$ S complex. Furthermore, we found that RGS11/G $\beta 5$ S can directly bind to mGluR6, a receptor enriched at the dendritic tips. This binding did not compete with R9AP association, arguing that the entire RGS11/G $\beta 5$ S/R9AP complex could be recruited by the receptor. Although detailed mechanisms of this interaction remain to be elucidated, this finding provides an additional example to the growing evidence that R7 RGS proteins and their orthologs can directly interact with G-protein-coupled receptors (Kovoor et al., 2005; Ballon et al., 2006; Psifogeorgou et al., 2007).

In the process of this study, we made two general observations that help clarify outstanding questions in retina biology beyond the function of RGS proteins. First, we report that the P185S mutation (nob4) in the ligand binding domain of mGluR6 destabilizes mGluR6 protein, arguing that the expression of this G-protein-coupled receptor is dependent on the glutamate binding. Second, we found that elimination of mGluR6 leads to the failure of the bipolar cells to establish synaptic connections with the photoreceptor terminals, suggesting that signaling through mGluR6 is required for proper synaptic connectivity of the ONbipolar cells.

Finally, the implications of RGS11 complex targeting to the mGluR6 receptor for signal transduction in ON-bipolar neurons remains unresolved. ON-bipolar neurons are known to use a G-protein-coupled signal transduction cascade for relaying to the retinal circuitry the light-induced changes in glutamate released from the photoreceptor terminals (for review, see Vardi et al., 2002; Snellman et al., 2008). In darkness, the glutamate is primarily sensed by the mGluR6 (Nomura et al., 1994; Masu et al., 1995; Vardi et al., 1998; Miller, 2008), which signals by constantly activating the G-protein $\mathrm{G}_{\mathrm{o}}$ (Nawy, 1999; Dhingra et al., 2000). Activated $G_{o}$ either directly or via coupling to second messengers holds closed an unidentified cation channel, thus hyperpolarizing the cell (Nawy and Jahr, 1990; Shiells and Falk, 1990; Okawa and Sampath, 2007). Suppression of the glutamate release during light excitation results in the reduction of the $\mathrm{G} \alpha_{\mathrm{o}}$ activation, thereby leading to the opening of channels, depolarizing the membrane potential. Because the G-protein inactivation is a required step for opening of the channel, the speed of the GTP hydrolysis on the $\mathrm{G} \alpha_{\mathrm{o}}$ should determine the raising phase of the ON-bipolar light response (Dhingra et al., 2004). Thus, the GAP activity of the RGS proteins toward $\mathrm{G} \alpha_{\mathrm{o}}$ is expected to contribute significantly to shaping the onset of the ON-bipolar cell response to light excitation. In agreement with a previous report (Hooks et al., 2003), we found that RGS11/G $\beta 5$ S is a very efficient GAP for $\mathrm{G} \alpha_{\mathrm{o}}$, capable of accelerating the GTP hydrolysis rate on this G-protein by an order of magnitude (Fig. 8). However, examination of the rod ON-bipolar cell responses in RGS11 knock-out mice revealed no significant differences in either the dark-adapted light response or during adaptation to background light compared with wild-type littermates (Fig. 9). The most straightforward explanation for this result is that the elimination of the RGS11/G $\beta 5$ S/R9AP complex was not sufficient to substantially reduce the GAP activity toward the $\mathrm{G} \alpha_{\mathrm{o}}$. In light of this finding, it appears likely that, in the ON-bipolar cells, $\mathrm{G} \alpha_{\mathrm{o}}$ inactivation can be controlled by multiple RGS proteins that contribute to the aggregate GAP activity in the cell. Indeed, in addition to RGS11, bipolar cells are known to also contain the homologous RGS7 (Morgans et al., 2007; Rao et al., 2007; Cao et al., 2008) and Ret-RGS1 (Dhingra et al., 2004), both of which show significant GAP activities toward $\mathrm{G} \alpha_{\mathrm{o}}$. Therefore, the delineation of the GAP activities in setting the kinetics of the ON-bipolar cells to light will require the analysis of mouse models with simultaneous elimination of several RGS proteins. Likewise, future experiments will need to address the functional significance that redundancy in RGS proteins plays for establishing the physiology of ON-bipolar cells. 


\section{References}

Anderson GR, Semenov A, Song JH, Martemyanov KA (2007a) The membrane anchor R7BP controls the proteolytic stability of the striatal specific RGS protein, RGS9-2. J Biol Chem 282:4772-4781.

Anderson GR, Lujan R, Semenov A, Pravetoni M, Posokhova EN, Song JH, Uversky V, Chen CK, Wickman K, Martemyanov KA (2007b) Expression and localization of RGS9-2/G 5/R7BP complex in vivo is set by dynamic control of its constitutive degradation by cellular cysteine proteases. J Neurosci 27:14117-14127.

Baker SA, Haeri M, Yoo P, Gospe SM 3rd, Skiba NP, Knox BE, Arshavsky VY (2008) The outer segment serves as a default destination for the trafficking of membrane proteins in photoreceptors. J Cell Biol 183:485-498.

Ballon DR, Flanary PL, Gladue DP, Konopka JB, Dohlman HG, Thorner J (2006) DEP-domain-mediated regulation of GPCR signaling responses. Cell 126:1079-1093.

Blundell J, Hoang CV, Potts B, Gold SJ, Powell CM (2008) Motor coordination deficits in mice lacking RGS9. Brain Res 1190:78-85.

Burns ME, Arshavsky VY (2005) Beyond counting photons: trials and trends in vertebrate visual transduction. Neuron 48:387-401.

Cabrera JL, de Freitas F, Satpaev DK, Slepak VZ (1998) Identification of the G 35 -RGS7 protein complex in the retina. Biochem Biophys Res Commun 249:898-902.

Cao Y, Song H, Okawa H, Sampath AP, Sokolov M, Martemyanov KA (2008) Targeting of RGS7/Gbeta5 to the dendritic tips of ON-bipolar cells is independent of its association with membrane anchor R7BP. J Neurosci 28:10443-10449.

Chen CK, Eversole-Cire P, Zhang H, Mancino V, Chen YJ, He W, Wensel TG, Simon MI (2003) Instability of GGL domain-containing RGS proteins in mice lacking the $\mathrm{G}$ protein $\beta$-subunit G $\beta 5$. Proc Natl Acad Sci U S A 100:6604-6609.

Dhingra A, Lyubarsky A, Jiang M, Pugh EN Jr, Birnbaumer L, Sterling P, Vardi N (2000) The light response of ON bipolar neurons requires $\mathrm{G} \alpha_{\mathrm{o}}$. J Neurosci 20:9053-9058.

Dhingra A, Faurobert E, Dascal N, Sterling P, Vardi N (2004) A retinalspecific regulator of G-protein signaling interacts with $\mathrm{G} \alpha_{\mathrm{o}}$ and accelerates an expressed metabotropic glutamate receptor 6 cascade. J Neurosci 24:5684-5693.

Drenan RM, Doupnik CA, Boyle MP, Muglia LJ, Huettner JE, Linder ME, Blumer KJ (2005) Palmitoylation regulates plasma membrane-nuclear shuttling of R7BP, a novel membrane anchor for the RGS7 family. J Cell Biol 169:623-633.

Dunn FA, Doan T, Sampath AP, Rieke F (2006) Controlling the gain of rod-mediated signals in the mammalian retina. J Neurosci 26:3959-3970.

Ghosh KK, Bujan S, Haverkamp S, Feigenspan A, Wässle H (2004) Types of bipolar cells in the mouse retina. J Comp Neurol 469:70-82.

Giudice A, Gould JA, Freeman KB, Rastan S, Hertzog P, Kola I, Iannello RC (2001) Identification and characterization of alternatively spliced murine Rgs11 isoforms: genomic structure and gene analysis. Cytogenet Cell Genet 94:216-224.

Gold SJ, Ni YG, Dohlman HG, Nestler EJ (1997) Regulators of G-protein signaling (RGS) proteins: region-specific expression of nine subtypes in rat brain. J Neurosci 17:8024-8037.

Hollinger S, Hepler JR (2002) Cellular regulation of RGS proteins: modulators and integrators of $\mathrm{G}$ protein signaling. Pharmacol Rev 54:527-559.

Hooks SB, Waldo GL, Corbitt J, Bodor ET, Krumins AM, Harden TK (2003) RGS6, RGS7, RGS9, and RGS11 stimulate GTPase activity of Gi family G-proteins with differential selectivity and maximal activity. J Biol Chem 278:10087-10093.

Hooks SB, Martemyanov K, Zachariou V (2008) A role of RGS proteins in drug addiction. Biochem Pharmacol 75:76-84.

Hu G, Wensel TG (2002) R9AP, a membrane anchor for the photoreceptor GTPase accelerating protein, RGS9-1. Proc Natl Acad Sci U SA 99:9755-9760.

Inoue T, Tanaka T, Suzuki SC, Takeichi M (1998) Cadherin-6 in the developing mouse brain: expression along restricted connection systems and synaptic localization suggest a potential role in neuronal circuitry. Dev Dyn 211:338-351.

Keresztes G, Mutai H, Hibino H, Hudspeth AJ, Heller S (2003) Expression patterns of the RGS9-1 anchoring protein R9AP in the chicken and mouse suggest multiple roles in the nervous system. Mol Cell Neurosci 24:687-695.

Keresztes G, Martemyanov KA, Krispel CM, Mutai H, Yoo PJ, Maison SF,
Burns ME, Arshavsky VY, Heller S (2004) Absence of the RGS9/G $\beta 5$ GTPase-activating complex in photoreceptors of the R9AP knockout mouse. J Biol Chem 279:1581-1584.

Kovoor A, Seyffarth P, Ebert J, Barghshoon S, Chen CK, Schwarz S, Axelrod JD, Cheyette BN, Simon MI, Lester HA, Schwarz J (2005) D2 dopamine receptors colocalize regulator of G-protein signaling 9-2 (RGS9-2) via the RGS9 DEP domain, and RGS9 knock-out mice develop dyskinesias associated with dopamine pathways. J Neurosci 25:2157-2165.

Krumins AM, Gilman AG (2002) Assay of RGS protein activity in vitro using purified components. Methods Enzymol 344:673-685.

Maddox DM, Vessey KA, Yarbrough GL, Invergo BM, Cantrell DR, Inayat S, Balannik V, Hicks WL, Hawes NL, Byers S, Smith RS, Hurd R, Howell D, Gregg RG, Chang B, Naggert JK, Troy JB, Pinto LH, Nishina PM, McCall MA (2008) Allelic variance between GRM6 mutants, Grm6nob3 and Grm6nob4 results in differences in retinal ganglion cell visual responses. J Physiol 586:4409-4424.

Makino ER, Handy JW, Li T, Arshavsky VY (1999) The GTPase activating factor for transducin in rod photoreceptors is the complex between RGS9 and type 5 G protein $\beta$ subunit. Proc Natl Acad Sci U S A 96:1947-1952.

Martemyanov KA, Lishko PV, Calero N, Keresztes G, Sokolov M, Strissel KJ, Leskov IB, Hopp JA, Kolesnikov AV, Chen CK, Lem J, Heller S, Burns ME, Arshavsky VY (2003) The DEP domain determines subcellular targeting of the GTPase activating protein RGS9 in vivo. J Neurosci 23:10175-10181.

Martemyanov KA, Yoo PJ, Skiba NP, Arshavsky VY (2005) R7BP, a novel neuronal protein interacting with RGS proteins of the R7 family. J Biol Chem 280:5133-5136.

Masu M, Iwakabe H, Tagawa Y, Miyoshi T, Yamashita M, Fukuda Y, Sasaki H, Hiroi K, Nakamura Y, Shigemoto R, Takada M, Nakamura K, Nakao K, Katsuki M, Nakanishi S (1995) Specific deficit of the ON response in visual transmission by targeted disruption of the mGluR6 gene. Cell 80:757-765.

Miller RF (2008) Cell communication mechanisms in the vertebrate retina the proctor lecture. Invest Ophthalmol Vis Sci 49:5184-5198.

Morgans CW, Wensel TG, Brown RL, Perez-Leon JA, Bearnot B, Duvoisin RM (2007) Gbeta5-RGS complexes co-localize with mGluR6 in retinal ON-bipolar cells. Eur J Neurosci 26:2899-2905.

Nawy S (1999) The metabotropic receptor mGluR6 may signal through $\mathrm{G}(\mathrm{o})$, but not phosphodiesterase, in retinal bipolar cells. J Neurosci 19:2938-2944.

Nawy S, Jahr CE (1990) Suppression by glutamate of cGMP-activated conductance in retinal bipolar cells. Nature 346:269-271.

Nomura A, Shigemoto R, Nakamura Y, Okamoto N, Mizuno N, Nakanishi S (1994) Developmentally regulated postsynaptic localization of a metabotropic glutamate receptor in rat rod bipolar cells. Cell 77:361-369.

Okawa H, Sampath AP (2007) Optimization of single-photon response transmission at the rod-to-rod bipolar synapse. Physiology (Bethesda) 22:279-286.

Pinto LH, Vitaterna MH, Shimomura K, Siepka SM, Balannik V, McDearmon EL, Omura C, Lumayag S, Invergo BM, Glawe B, Cantrell DR, Inayat S, Olvera MA, Vessey KA, McCall MA, Maddox D, Morgans CW, Young B, Pletcher MT, Mullins RF, Troy JB, Takahashi JS (2007) Generation, identification and functional characterization of the nob4 mutation of Grm6 in the mouse. Vis Neurosci 24:111-123.

Psifogeorgou K, Papakosta P, Russo SJ, Neve RL, Kardassis D, Gold SJ, Zachariou V (2007) RGS9-2 is a negative modulator of mu-opioid receptor function. J Neurochem 103:617-625.

Rao A, Dallman R, Henderson S, Chen CK (2007) Gbeta5 is required for normal light responses and morphology of retinal ON-bipolar cells. J Neurosci 27:14199-14204.

Ross EM (2002) Quantitative assays for GTPase-activating proteins. Methods Enzymol 344:601-617.

Ross EM, Wilkie TM (2000) GTPase-activating proteins for heterotrimeric G proteins: Regulators of G protein signaling (RGS) and RGS-like proteins. Annu Rev Biochem 69:795-827.

Sampath AP, Strissel KJ, Elias R, Arshavsky VY, McGinnis JF, Chen J, Kawamura S, Rieke F, Hurley JB (2005) Recoverin improves rodmediated vision by enhancing signal transmission in the mouse retina. Neuron 46:413-420.

Sato S, Omori Y, Katoh K, Kondo M, Kanagawa M, Miyata K, Funabiki K, Koyasu T, Kajimura N, Miyoshi T, Sawai H, Kobayashi K, Tani A, Toda T, Usukura J, Tano Y, Fujikado T, Furukawa T (2008) Pikachurin, a dys- 
troglycan ligand, is essential for photoreceptor ribbon synapse formation. Nat Neurosci 11:923-931.

Schmitz F, Königstorfer A, Südhof TC (2000) RIBEYE, a component of synaptic ribbons: a protein's journey through evolution provides insight into synaptic ribbon function. Neuron 28:857-872.

Shiells RA, Falk G (1990) Glutamate receptors of rod bipolar cells are linked to a cyclic GMP cascade via a G-protein. Proc Biol Sci 242:91-94.

Skiba NP, Martemyanov KA, Elfenbein A, Hopp JA, Bohm A, Simonds WF, Arshavsky VY (2001) RGS9-G $\beta 5$ substrate selectivity in photoreceptors: opposing effects of constituent domains yield high affinity of RGS interaction with the G protein-effector complex. J Biol Chem 276:37365-37372.

Snellman J, Kaur T, Shen Y, Nawy S (2008) Regulation of ON bipolar cell activity. Prog Retin Eye Res 27:450-463.

Snow BE, Krumins AM, Brothers GM, Lee SF, Wall MA, Chung S, Mangion J,
Arya S, Gilman AG, Siderovski DP (1998) A G protein gamma subunitlike domain shared between RGS11 and other RGS proteins specifies binding to G $\beta 5$ subunits. Proc Natl Acad Sci U S A 95:13307-13312.

Song JH, Waataja JJ, Martemyanov KA (2006) Subcellular targeting of RGS9-2 is controlled by multiple molecular determinants on its membrane anchor, R7BP. J Biol Chem 281:15361-15369.

Song JH, Song H, Wensel TG, Sokolov M, Martemyanov KA (2007) Localization and differential interaction of R7 RGS proteins with their membrane anchors R7BP and R9AP in neurons of vertebrate retina. Mol Cell Neurosci 35:311-319.

Vardi N, Morigiwa K, Wang TL, Shi YJ, Sterling P (1998) Neurochemistry of the mammalian cone "synaptic complex." Vision Res 38:1359-1369.

Vardi N, Dhingra A, Zhang L, Lyubarsky A, Wang TL, Morigiwa K (2002) Neurochemical organization of the first visual synapse. Keio J Med 51:154-164. 